\title{
Pacemaker Rate and Depolarization Block in Nigral Dopamine Neurons: A Somatic Sodium Channel Balancing Act
}

\author{
Kristal R. Tucker, ${ }^{1}$ Marco A. Huertas, ${ }^{2}$ John P. Horn, ${ }^{3}$ Carmen C. Canavier, ${ }^{2}$ and Edwin S. Levitan ${ }^{1}$ \\ ${ }^{1}$ Department of Pharmacology and Chemical Biology, University of Pittsburgh School of Medicine, Pittsburgh, Pennsylvania 15261; ${ }^{2}$ Department of Cell \\ Biology and Anatomy and Neuroscience Center of Excellence, Louisiana State University Health Sciences Center, New Orleans, Louisiana 70112; and \\ ${ }^{3}$ Department of Neurobiology and Center for Neuroscience, University of Pittsburgh School of Medicine, Pittsburgh, Pennsylvania 15261
}

\begin{abstract}
Midbrain dopamine (DA) neurons are slow intrinsic pacemakers that undergo depolarization (DP) block upon moderate stimulation. Understanding DP block is important because it has been correlated with the clinical efficacy of chronic antipsychotic drug treatment. Here we describe how voltage-gated sodium $\left(\mathrm{Na}_{\mathrm{V}}\right)$ channels regulate DP block and pacemaker activity in DA neurons of the substantia nigra using rat brain slices. The distribution, density, and gating of $\mathrm{Na}_{\mathrm{V}}$ currents were manipulated by blocking native channels with tetrodotoxin and by creating virtual channels and anti-channels with dynamic clamp. Although action potentials initiate in the axon initial segment and $\mathrm{Na}_{\mathrm{V}}$ channels are distributed in multiple dendrites, selective reduction of $\mathrm{Na}_{\mathrm{V}}$ channel activity in the soma was sufficient to decrease pacemaker frequency and increase susceptibility to DP block. Conversely, increasing somatic $\mathrm{Na}_{V}$ current density raised pacemaker frequency and lowered susceptibility to DP block. Finally, when $\mathrm{Na}_{\mathrm{V}}$ currents were restricted to the soma, pacemaker activity occurred at abnormally high rates due to excessive local subthreshold $\mathrm{Na}_{\mathrm{V}}$ current. Together with computational simulations, these data show that both the slow pacemaker rate and the sensitivity to DP block that characterizes DA neurons result from the low density of somatic $\mathrm{Na}_{\mathrm{V}}$ channels. More generally, we conclude that the somatodendritic distribution of $\mathrm{Na}_{\mathrm{V}}$ channels is a major determinant of repetitive spiking frequency.
\end{abstract}

\section{Introduction}

Substantia nigra (SN) dopamine (DA) neurons exhibit slow intrinsic pacemaker activity (Kita et al., 1986; Hainsworth et al., 1991). Although voltage-gated calcium channels have been implicated in driving pacemaker activity (Nedergaard et al., 1993; Mercuri et al., 1994; Chan et al., 2007; Puopolo et al., 2007; Putzier et al., 2009a), voltage-gated sodium $\left(\mathrm{Na}_{\mathrm{V}}\right)$ channels also contribute to the slow depolarization (DP) phase leading to action potential (AP) initiation (Puopolo et al., 2007). Furthermore, $\mathrm{Na}_{\mathrm{V}}$ channels are responsible for the initiation of APs in the axon initial segment (AIS) and their subsequent propagation in the axon, dendrites, and soma, which in turn triggers DA release from terminals and dendrites (Grace and Bunney, 1983b; Santiago et al., 1992; Häusser et al., 1995; Gentet and Williams, 2007; Blythe et al., 2009). Thus, $\mathrm{Na}_{\mathrm{V}}$ channels are major determinants of nigral DA neuron activity and function.

Interestingly, the efficacy of antipsychotic drugs is correlated with induction of chronic DP block in DA neurons

Received March 13, 2012; revised Aug. 9, 2012; accepted Aug. 17, 2012.

Author contributions: K.R.T., J.P.H., C.C.C., and E.S.L. designed research; K.R.T., M.A.H., and C.C.C. performed research; K.R.T., M.A.H., J.P.H., and E.S.L. analyzed data; K.R.T., J.P.H., C.C.C., and E.S.L. wrote the paper.

This work was supported by National Institutes of Health Grants R01NS061097 and F32NS078994.

The authors declare no competing financial interests.

Correspondence should be addressed to Dr. Edwin S. Levitan, Department of Pharmacology and Chemical Biology, E1351 Biomedical Science Tower, University of Pittsburgh, Pittsburgh, PA 15261. E-mail: elevitan@pitt.edu.

DOI:10.1523/JNEUROSCI.1251-12.2012

Copyright $\odot 2012$ the authors $\quad 0270-6474 / 12 / 3214519-13 \$ 15.00 / 0$
(Chiodo and Bunney, 1983; White and Wang, 1983a,b; Grace and Bunney, 1986; Esposito and Bunney, 1989; Skarsfeldt and Perregaard, 1990; Skarsfeldt, 1992; Valenti et al., 2011). With acute excitation, DP block is preceded by attenuation of AP amplitude, broadening of each successive spike, and the eventual failure of AP production (Richards et al., 1997; Blythe et al., 2009). A computational modeling study of DA neurons suggested that DP block may result from cumulative inactivation of $\mathrm{Na}_{\mathrm{V}}$ channels leading to an increase in AP threshold that eventually becomes so depolarized that APs cannot initiate (Kuznetsova et al., 2010). However, this model, which did not take into account that in DA neurons APs propagate from the AIS through a dendrite into the soma, has not been tested experimentally. Thus, it is not known whether $\mathrm{Na}_{\mathrm{V}}$ channels in the AIS and/or soma determine susceptibility to DP block in intact SN DA neurons.

Here the role of $\mathrm{Na}_{\mathrm{V}}$ channels in SN DA neuron activity is investigated by manipulating $\mathrm{Na}_{\mathrm{V}}$ current magnitude, distribution, and gating with the dynamic clamp, a device that adds virtual channels via computationally generated currents injected through a patch pipette into the neuron. Specifically, virtual $\mathrm{Na}_{\mathrm{V}}$ conductance, which was based on native SN DA neuron currents characterized in nucleated patches (Seutin and Engel, 2010), was added or subtracted from the soma of SN DA neurons in the brain slice. Even though APs initiate in the AIS, somatic $\mathrm{Na}_{\mathrm{V}}$ channels are shown to control the bal- 
ance between pacemaker frequency and susceptibility to DP block in nigral DA neurons.

\section{Materials and Methods}

Solutions and reagents. Sucrose modified artificial CSF (s-ACSF) contained the following (in $\mathrm{mm}$ ): $87 \mathrm{NaCl}, 75$ sucrose, $2.5 \mathrm{KCl}, 25 \mathrm{NaHCO}_{3}, 1.25$ $\mathrm{NaH}_{2} \mathrm{PO}_{4}, 0.5 \mathrm{CaCl}_{2}, 7 \mathrm{MgSO}_{4}, 25$ glucose, 0.15 ascorbic acid, and 1 kynurenic acid, pH 7.4. Normal ACSF contained the following (in $\mathrm{mm}$ ): 124 $\mathrm{NaCl}, 4 \mathrm{KCl}, 25.7 \mathrm{NaHCO}_{3}, 1.25 \mathrm{NaH}_{2} \mathrm{PO}_{4}, 2.45$ $\mathrm{CaCl}_{2}, 1.2 \mathrm{MgSO}_{4}, 11$ glucose, and 0.15 ascorbic acid, $\mathrm{pH}$ 7.4. Adult perfusion and brain slice solution contained the following (in $\mathrm{mM}$ ): 105 $\mathrm{N}$-methyl-D-glucamine-Cl, $105 \mathrm{HCl}, 2.5 \mathrm{KCl}, 1.2$ $\mathrm{NaH}_{2} \mathrm{PO}_{4}, 26 \mathrm{NaHCO}_{3}, 25$ glucose, $10 \mathrm{MgSO}_{4}$, $0.5 \mathrm{CaCl}_{2}, 5$ ascorbic acid, 3 sodium pyruvate, 2 thiourea, and 1 kynurenic acid, $\mathrm{pH}$ 7.4. The pipette solution contained the following (in $\mathrm{mM}$ ): 120 potassium gluconate, $20 \mathrm{KCl}, 10$ HEPES, 2 $\mathrm{MgCl}_{2}, 0.1$ EGTA, and 1.2 ATP disodium salt, $\mathrm{pH}$ 7.3. All salts were purchased from either SigmaAldrich or Thermo-Fisher Scientific. Tetrodotoxin with citrate was purchased from Alomone Labs.

Midbrain slice preparation. All experiments were conducted according to University of Pittsburgh Institutional Animal Care and Use Committee approved protocols. Midbrain slice preparations from postnatal days 14-21 (P14-P21) male Sprague Dawley rats (Hilltop Laboratories) were performed as previously described (Putzier et al., 2009b). A small subset of experiments was performed in slices from P42 male Sprague Dawley rats. These older rats were anesthetized with isoflurane, transcardially perfused with ice-cold carbogenated adult perfusion solution and decapitated (Peça et al., 2011; Ting and Feng, 2011). The brain was then quickly removed and placed into ice-cold, carbogenated s-ACSF for $\mathrm{P} 14-\mathrm{P} 21$ rats and ice-cold, carbogenated adult slice solution for $\mathrm{P} 42$ rats. Coronal midbrain slices $(250 \mu \mathrm{m})$ were cut using a Vibratome 3000 (The Vibratome Company) in the respective ice-cold, carbogenated solutions. Midbrain slices from P14-P21 rats were incubated in room temperature carbogenated s-ACSF in an interface chamber for at least $1 \mathrm{~h}$ and then held in room temperature normal ACSF in the interface chamber until use. Midbrain slices from P42 rats were incubated in room-temperature carbogenated adult slice solution in an interface chamber for $30 \mathrm{~min}$, during which time the adult slice solution was slowly replaced by the room-temperature carbogenated normal ACSF (Peça et al., 2011; Ting and Feng, 2011). These slices were then maintained for at least another 30 min in room temperature normal ACSF in the interface chamber before use.

Electrophysiology. Patch electrodes were fabricated from Corning 7056 Patch Glass (Warner Instruments) and coated near the tip with beeswax to reduce the pipette capacitance. Carbogenated normal ACSF was used for bath perfusion of midbrain slices at a rate of $2 \mathrm{ml} / \mathrm{min}$. SN pars compacta DA neurons were identified by location and electrophysiological characteristics as described previously (Grace and Bunney, 1983a; Lacey et al., 1989; Richards et al., 1997).

Dynamic clamp is a modified current-clamp technique that creates virtual channels in a living cell by dynamically adjusting the current injected in response to real-time changes in the membrane potential based on previously modeled channel behavior. The virtual NMDA receptor (NMDAR) conductance in the present experiments used equations from previous dynamic clamp studies of DA neurons (Deister et al., 2009; Putzier et al., 2009a). Because the virtual $\mathrm{Na}_{\mathrm{V}}$ channel was based on indicated below each trace.
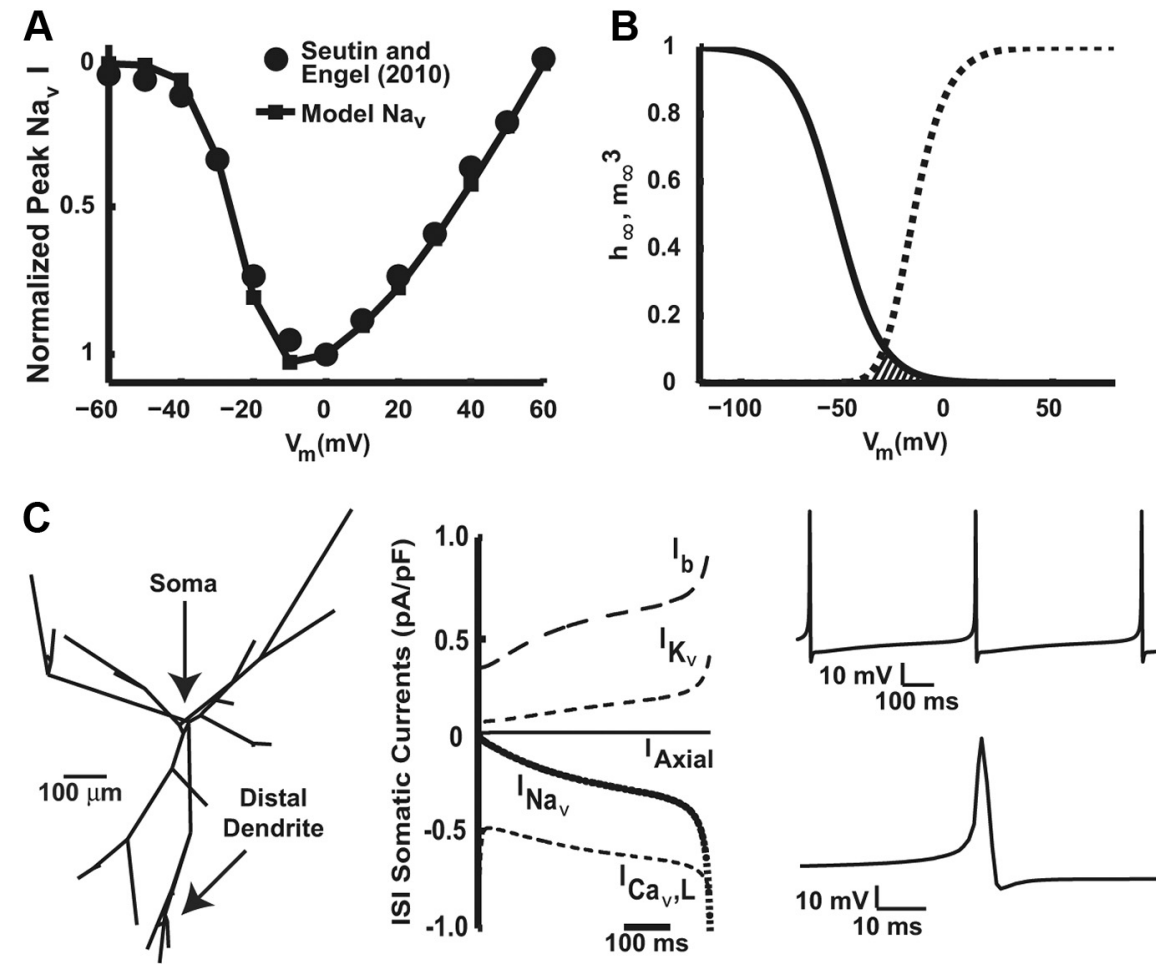

Figure 1. Sodium channel and SN DA neuron model descriptions. A, Comparison of the peak $\mathrm{Na}_{V}$ current/voltage response measured from SN DA neuron nucleated patches by Seutin and Engel (2010) (circles) and the modeled $\mathrm{Na}_{v}$ current/voltage response based on fitting those data (squares and line). $\boldsymbol{B}$, Steady-state inactivation ( $h_{\infty} ;$ solid line) and activation ( $m_{\infty}^{3}$; dashed axon is shown. Middle, Somatic currents flowing during the interspike interval (ISI). $I_{K V}=$ composite voltage-gated potassium 政 Right, Simulated pacing activity of the model neuron as measured from the soma (top trace) and a single AP (bottom trace). Scale

Table 1. Time and voltage dependence of model gating variables

\begin{tabular}{|c|c|c|c|}
\hline & $x_{\text {half }}(\mathrm{mV})$ & $x_{k}(\mathrm{mV})$ & Time constants: $\operatorname{tau}_{x}(\mathrm{~ms})$ \\
\hline$m$ & -30.0907 & 9.7264 & $\begin{array}{l}0.01+1 /(a+b), a=-(15.6504+0.4043 \mathrm{~V}) / \\
{[\exp (-19.565-0.50542 \mathrm{v})-1]} \\
b=3.0212 \exp \left(-7.4630 \times 10^{-3} \mathrm{v}\right)\end{array}$ \\
\hline$h_{f}$ & -54.0289 & -10.7665 & $\begin{array}{l}0.4+1 /(a+b), a=5.0754 \times 10^{-4} \exp \left(-6.3213 \times 10^{-2} v\right) \\
b=9.7529 \exp (0.13442 \mathrm{v})\end{array}$ \\
\hline$h_{s}$ & -54.0289 & -10.7665 & $\begin{array}{l}0.4+1 /(a+b), a=1.3134 \times 10^{-2} \exp \left(8.5636 \times 10^{-4} v\right) \\
b=13.165 \exp (0.14556 \mathrm{v})\end{array}$ \\
\hline$n$ & -25 & 12 & $1+10 \exp \left(-\{\ln [1+0.05(v+40)] / 0.05\}^{2} / 300\right)$ \\
\hline I & -40 & 10 & $\begin{array}{l}1 /(a+b), a=-0.020876(v+39.726) /(\exp ((v+39.726) / \\
\quad 4.711)-1) \\
b=0.19444 \exp (-(v+15.338) / 224.21)\end{array}$ \\
\hline
\end{tabular}

nucleated-patch voltage-clamp recordings at $25^{\circ} \mathrm{C}$ (Seutin and Engel, 2010), all recordings were performed at $25^{\circ} \mathrm{C}$.

Whole-cell recordings in the current-clamp and dynamic clamp configurations were performed as previously described (Kullmann et al., 2004; Putzier et al., 2009b). Briefly, the current-clamp and dynamic clamp recording system included an A-M Systems PatchClamp Amplifier Model 2400 (National Instruments), a National Instruments PXI-1002 CPU for real-time loop computation, and an IBM MT-M 8310-47U CPU with Pentium 4 processor used for userG-clamp interface. LabVIEW-RT 8.1 (National Instruments) was used to run the G-clamp 2.02 software (http://hornlab.neurobio.pitt. edu). Current-clamp and dynamic clamp measurements were performed with a feedback loop rate of $20 \mathrm{kHz}$, which has been 

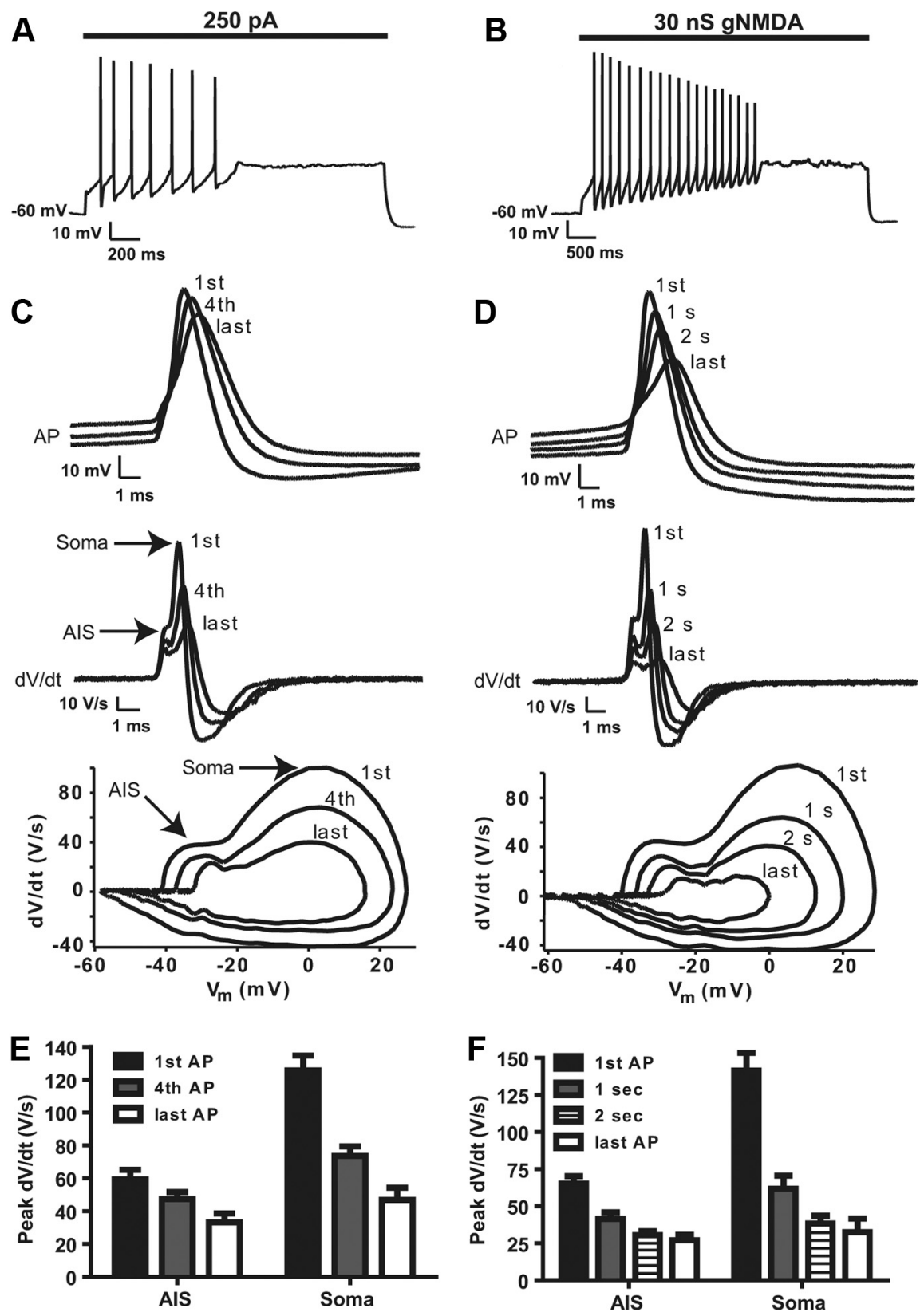

Figure 2. Inward currents of the AIS and soma are reduced during DP block induction. Representative recordings from SN DA neurons current-clamped at $-60 \mathrm{mV}$ followed by $(\boldsymbol{A})$ a $2 \mathrm{~s}, 250 \mathrm{pA}$ current injection and $(\boldsymbol{B})$ a $5 \mathrm{~s}$ dynamic clamp application of $30 \mathrm{nS}$ of virtual NMDAR conductance to induce DP block. $C$, The first, fourth, and last APs (top of the example trace in $A$ ) and their corresponding $d V / d t$ (middle) and phase plane (bottom) plots. D, The APs (top) in the first position, at $1 \mathrm{~s}$ of stimulation, at $2 \mathrm{~s}$ of stimulation, and in the last position of the example trace in $B$ and their corresponding $d V / d t$ (middle) and phase plane (bottom) plots. The arrows in Cindicate the peak net current flowing during the AIS and somatic portions of the AP. An upward deflection indicates a net inward current and a downward deflection indicates a net outward current. Peak AIS and somatic $d V / d t$ for $(\boldsymbol{D})$ current injection and $(\boldsymbol{F})$ virtual NMDA-induced DP block. Error bars indicate the mean \pm SEM (for current injection $n=9 ;$ for $\operatorname{NMDA} n=7$ ).

Table 2. Quantification of AP and inward current changes during DP block development

\begin{tabular}{lllllll}
\hline & $\begin{array}{l}\text { AP } \\
\text { position }\end{array}$ & $\begin{array}{l}\text { AP peak } \\
(\mathrm{mV})\end{array}$ & $\begin{array}{l}\text { AP AHP } \\
(\mathrm{mV})\end{array}$ & $\begin{array}{l}\text { AP threshold } \\
(\mathrm{mV})\end{array}$ & $\begin{array}{l}\text { Peak AIS } \\
\mathrm{dV} / \mathrm{dt}(\mathrm{V} / \mathrm{s})\end{array}$ & $\begin{array}{l}\text { Peak somatic } \\
\text { dV/dt }(\mathrm{V} / \mathrm{s})\end{array}$ \\
\hline Current & 1st & $26.5 \pm 1.4$ & $-56.5 \pm 1.3$ & $-40.8 \pm 1.8$ & $59.4 \pm 5.8$ & $125.7 \pm 9.0$ \\
$n=9$ & 4th & & & & $47.3 \pm 4.4$ & $73.6 \pm 5.9$ \\
& Last & $13.8 \pm 3.3$ & $-48.9 \pm 1.1$ & $-31.5 \pm 1.7$ & $33.2 \pm 5.4$ & $46.9 \pm 7.3$ \\
gNMDA & 1st & $28.0 \pm 1.4$ & $-60.2 \pm 1.8$ & $-41.4 \pm 1.2$ & $65.2 \pm 5.0$ & $141.3 \pm 12.1$ \\
$n=7$ & $1 \mathrm{~s}$ & & & & $41.4 \pm 4.5$ & $61.7 \pm 8.8$ \\
& 2s & & & & $30.4 \pm 2.7$ & $38.3 \pm 5.3$ \\
& Last & $11.8 \pm 2.7$ & $-53.8 \pm 2.7$ & $-26.7 \pm 1.4$ & $26.9 \pm 3.7$ & $32.8 \pm 9.4$ \\
\hline
\end{tabular}

previously shown to be sufficient for fast $\mathrm{Na}_{\mathrm{V}}$ conductances (Kullmann et al., 2004; Bettencourt et al., 2008).

The mean and SEM pipette, series and membrane resistances were $3.34 \pm 0.09,12.92 \pm$ 0.96 , and $218.7 \pm 8.8 \mathrm{M} \Omega$, respectively, for 91 recordings before compensation. Series resistance was monitored throughout each experiment and compensated using the bridge circuitry of the amplifier. The average membrane capacitance was $149.2 \pm 3.9 \mathrm{pF}$ for 91 cells. Only cells that were spontaneously active after breaking through to the whole-cell configuration and before tetrodotoxin (TTX) treatment were included in the results presented here. Furthermore, dynamic clampinduced changes in activity were reversible.

In the current-clamp recordings, SN DA neurons were held at $-60 \mathrm{mV}$ with bias current to prevent spontaneous pacing in between $2 \mathrm{~s}, 50 \mathrm{pA}$ current steps from -100 to $300 \mathrm{pA}$ with a $7 \mathrm{~s}$ interpulse interval. With this paradigm, the characteristic sag in the membrane potential in response to hyperpolarization, slow pacemakerlike activity with small DPs, and DP block with larger DPs could be monitored before and after treatment. Synaptic conductance-induced DP block was elicited by current-clamping the membrane potential to $-60 \mathrm{mV}$ and adding 30 $\mathrm{nS}$ of virtual NMDA conductance for $5 \mathrm{~s}$ with dynamic clamp. In some experiments, virtual channels or current steps were added to freely pacing neurons.

Whole-cell voltage-clamp recordings were performed to determine the amount of time needed for full block of $\mathrm{Na}_{\mathrm{V}}$ channels by $1 \mu \mathrm{M}$ TTX in this midbrain slice preparation. Although voltage-clamp recording from intact neurons in slices is limited by incomplete space clamp, these recordings were used only to determine the time course of TTX action, not current kinetics. Normal ACSF was supplemented with $2 \mathrm{~mm} \mathrm{CoCl}_{2}$ and $15 \mathrm{~mm}$ TEA-Cl, and $\mathrm{K}$ gluconate and $\mathrm{KCl}$ were replaced by 140 $\mathrm{mm} \mathrm{CsCl}$ in the pipette solution to block voltage-sensitive potassium and calcium currents. The cells were held at $-60 \mathrm{mV}$ and stepped to $-40 \mathrm{mV}$ every $30 \mathrm{~s}$. After $2 \mathrm{~min}$ of baseline recording, $1 \mu \mathrm{M}$ TTX was superfused across the slice and the peak current amplitude was monitored until stable. The average time for complete block of sodium current was $6.6 \pm 1.0 \mathrm{~min}$ (range from 5 to $9 \mathrm{~min}$ ). Therefore, in current and dynamic clamp recordings in which $1 \mu \mathrm{M}$ or $10 \mathrm{~nm}$ TTX was used, the slices were superfused for at least $10 \mathrm{~min}$ or $20 \mathrm{~min}$, respectively, to ensure steady-state block.

Data analysis. AP characteristics and firing frequencies were measured and $d V / d t$ and phase plane analysis were conducted with IGOR Pro 5.05A (WaveMetrics) with the NeuroMatic v 2.00 plug-in (http://www.neuromatic.thinkrandom.com/index.html). AP height was measured from the AP peak to the trough of the afterhyperpolarization (AHP). AP threshold was measured from phase plane plots. Evoked AP frequency was measured from the peak of the first AP to the peak of the last AP during a stimulus. AP frequency during pacemaking was measured for a defined duration.

Virtual sodium channel description. The description of the $\mathrm{Na}_{\mathrm{V}}$ current kinetics used in both the modeling and dynamic clamp experiments was derived from rat SN DA nucleated patch voltage-clamp recordings pub- 
lished by Seutin and Engel (2010). The Seutin and Engel voltage dependence of activation $(m)$ and inactivation $\left(h_{f}\right)$ of the SN DA neuron $\mathrm{Na}_{\mathrm{V}}$ current assumed a Goldman-HodgkinKatz driving force and that no inactivation occurs before current peak. Those data were refitted because the dynamic clamp implementation used an ohmic drive, and at certain voltage ranges, the time scales for the activation and inactivation are not clearly separated. A slow component of inactivation $\left(h_{s}\right)$ was added to fit the data at $-120 \mathrm{mV}$ where two components of inactivation were clearly observed by Seutin and Engel (2010). Figure $1 \mathrm{~A}$ compares the $\mathrm{Na}_{\mathrm{V}}$ current-voltage relationships from Seutin and Engel's experimental data and the modeled/virtual $\mathrm{Na}_{\mathrm{V}}$ current. Table 1 summarizes the time and voltage-dependent gating variables calculated for the SN DA neuron $\mathrm{Na}_{\mathrm{V}}$ current and Figure $1 B$ shows the resulting voltage dependence of steady-state activation and inactivation for the modeled/virtual $\mathrm{Na}_{\mathrm{V}}$ channel.

Compartmental model. The SN DA neuron model was implemented in the NEURON simulation package (Hines and Carnavale, 1997) using a real DA neuron morphology (Vetter et al., 2001) downloaded from the neuromorpho. org database (Fig. 1C, left). Unless otherwise indicated, all compartments had the same conductance densities, in agreement with Häusser et al. (1995), who found similar fast sodium conductance on the soma and dendrites. The simulated membrane currents included: (1) the constitutively active GIRK conductance (Bradaia et al., 2009) and a sodium leak (Khaliq and Bean, 2010), which contribute to the net background current $\left(I_{b}\right),(2)$ an L-type calcium conductance $\left(\mathrm{I}_{\mathrm{Cav}, \mathrm{L}}\right)$ (Durante et al., 2004), (3) a composite potassium conductance $\left(I_{K v}\right)$ (Ding et al., 2011), and (4) the TTX-sensitive sodium conductance $\left(I_{\text {Nav }}\right)$ (Seutin and Engel, 2010) as described above. The currents in the model are given by $I_{b}=g_{\text {girk }}(v+85) /(1+\exp ((v+$ $45) / 20))+g_{\text {Naleak }}(v-60), I_{\text {Nav }}=g_{\text {Nav }} m^{3}\left(h_{f}+h_{s}\right)(v-60), I_{K v}=g_{K} n^{3}(\mathrm{v}$ $+85)$, and $I_{\mathrm{Cav}, \mathrm{L}}=g_{\mathrm{Cav}, \mathrm{L}} l(v-60)$, where the gating variables $m, h_{f}, h_{s}, n$, and $l$ obey equations of the form $d x / d t=\left(x_{\text {inf }}-x\right) / \operatorname{tau}_{x}$, with $x_{\text {inf }}=[1+$ $\left.\exp \left(-\left(v-x_{\text {half }}\right) / x_{k}\right)\right]^{-1}$. Maximal conductances in $\mu \mathrm{S} / \mathrm{cm}^{2}$ were $g_{\text {Nav }}=$ $3930, g_{K v}=3000, g_{\mathrm{Cav}, \mathrm{L}}=20.8, g_{\text {girk }}=226$, and $g_{\mathrm{Na}, \text { leak }}=33.75$. Values for $x_{\text {half }}, x_{k}$, and tau $x_{x}$ are given in Table 1 . The resulting interspike interval (ISI) currents are modeled in Figure 1C (middle).

The axial resistivity was $200 \mathrm{ohm} \mathrm{cm}$ and the capacitance was $1 \mu \mathrm{F} /$ $\mathrm{cm}^{2}$. The passive properties of the model were calibrated by confirming that when the neuron was held at $-60 \mathrm{mV}$ via current-clamp in the soma, additional small current pulses caused a change in somatic membrane potential to be reduced by $\sim 20 \%$ at a distance of $200 \mu \mathrm{m}$ from the soma along a primary dendrite (i.e., in agreement with Häusser et al., 1995). Some simulations were performed with a fixed $50 \mu$ s time step (sampling rate in dynamic clamp slice recordings) for the simulated dynamic clamp current injection only and a variable step size CVODE algorithm with small error tolerance for all other differential equations. These results (data not shown) were qualitatively similar to the ones reported in the text with variable step size updating for all state variables. Under these conditions, this model neuron was able to successfully replicate the characteristic slow pacemaker activity and broad APs of SN DA neurons (Fig. $1 C$, right).

Alternative models. Two other model neurons were created for comparison to the reduced somatodendritic model depicted in Figure 1. The first contained an axon coming off a dendrite that was composed of the same currents as the rest of the somatodendritic com- partments except that the $\mathrm{Na}_{\mathrm{V}}$ conductance in the axon was three times larger than in the soma, and the GIRK conductance was 1.11 times larger than in the soma. As little is known about the density, distribution, and composition of channels in SN DA neuron axons or AISs, these values were speculative and selected for their ability to produce natural pacemaker-like activity. The second model neuron was the same as described in Figure 1 with the addition of a calciumactivated SK potassium channel current and a calcium balance system (i.e., calcium buffering and pumping). When these models were compared with the reduced somatodendritic model of Figure 1, they were found to produce similar responses under identical experimental paradigms. Therefore, since the responses from the three models were similar and the currents defining the reduced model were better established, the reduced model simulations were reported here.

\section{Results}

DP block by inhibition of native $\mathrm{Na}_{\mathrm{v}}$ channels

To induce DP block, SN DA neurons were current-clamped to $-60 \mathrm{mV}$ and then depolarized by either a $250 \mathrm{pA}$ current injection or addition of $30 \mathrm{nS}$ of virtual NMDAR conductance generated by the dynamic clamp (Fig. $2 A, B$ ). Each stimulus induced APs that attenuated progressively (i.e., peak values dropped while AHPs and thresholds became depolarized) until activity ceased (Fig. 2A-D; Table 2). Current ( $I$ ) flowing during these responses is evident from $d V / d t$ because $d V / d t=$ $-I / C_{\mathrm{m}}$, where $C_{\mathrm{m}}$ equals membrane capacitance. Specifically, because APs in DA neurons initiate in the AIS and backpropagate into the soma, plotting $d V / d t$ versus time or membrane 
A

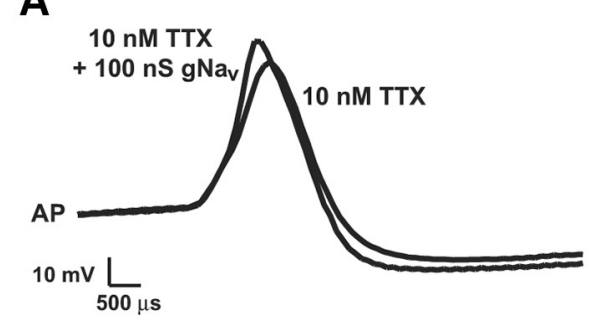

B
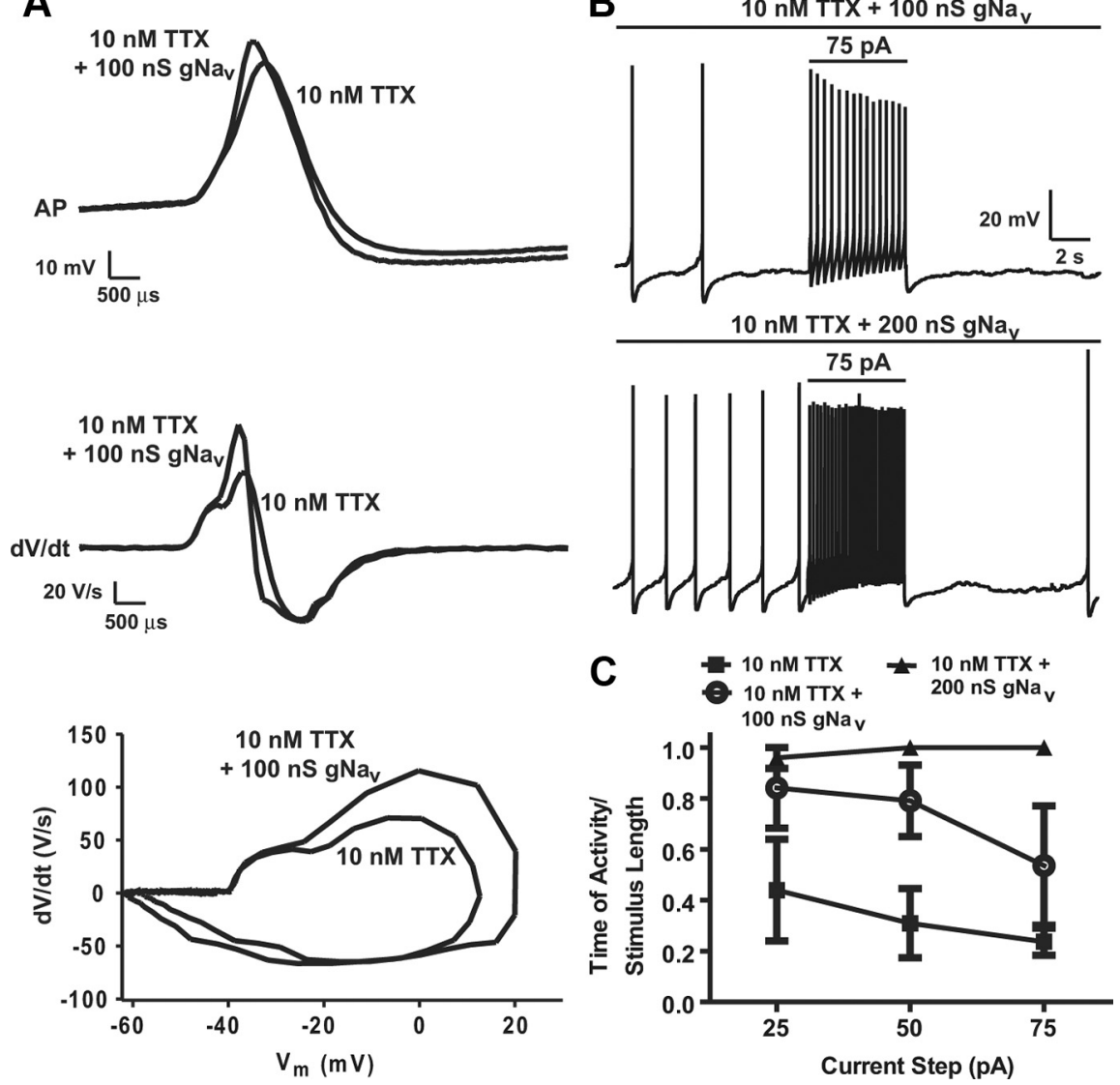

Figure 4. Addition of somatic $\mathrm{Na}_{\mathrm{V}}$ current decreases susceptibility to DP block induced by distributed submaximal $\mathrm{Na}_{\mathrm{v}}$ block. $\boldsymbol{A}$ Representative APs (top) from an SN DA neuron current-clamp recording in response to a $75 \mathrm{pA}$ current injection 20 min after $10 \mathrm{nM}$ TTX application (10 nм TTX; Fig. 2A) and with $100 \mathrm{nS}$ of virtual $\mathrm{Na}_{\mathrm{v}}$ added back to the soma with dynamic clamp (10 nм TTX +10 $\mathrm{nS} \mathrm{gNa}_{\mathrm{V}}$ ) and their corresponding $d V / d t$ (middle) and phase plane (bottom) plots. $B$, Current-clamp recording from the same cell represented in Figure $2 B$ after $10 \mathrm{~nm}$ TTX application with the addition of $100 \mathrm{nS}$ (top) and $200 \mathrm{nS}$ (bottom) of virtual $\mathrm{Na}_{\mathrm{V}}$ channel conductance applied throughout recording and responses to $5 \mathrm{~s}, 75 \mathrm{pA}$ current injections. C, Resistance to DP block as quantified by length of activity divided by the stimulus length plotted against the stimulus amplitude after $10 \mathrm{~nm}$ TTX alone (squares; Fig. 20), with the addition of $100 \mathrm{nS}$ (open circles), and $200 \mathrm{nS}$ (triangles) of virtual $\mathrm{Na}_{\mathrm{V}}$ channel conductance. Symbols and error bars indicate the mean $\pm S E$ of $3-5$ cells.

potential reveals two inward current components during the upstroke of the AP: initial activation of $\mathrm{Na}_{\mathrm{V}}$ channels in the AIS and subsequent $\mathrm{Na}_{\mathrm{V}}$ channel activation in the soma (Fig. $2 C, D$, middle and bottom). During development of DP block induced either by current injection or virtual NMDARs, both the AIS and somatic $\mathrm{Na}_{\mathrm{V}}$ currents revealed by $d V / d t$ plots progressively decreased (Fig. 2C-F; Table 2).

To determine whether the reduction of $\mathrm{Na}_{\mathrm{V}}$ channel activity is sufficient to increase susceptibility to DP block, a submaximal concentration (10 nM) of TTX was bath applied to the slice and SN DA neurons were depolarized with small current injections. At this dose, the $\mathrm{Na}_{\mathrm{V}}$ channel blocker slowed intrinsic pacemaker activity from $0.92 \pm 0.09 \mathrm{~Hz}$ to $0.49 \pm 0.22 \mathrm{~Hz}(n=5)$ and reduced AP amplitude from $88.9 \pm 4.5$ to $74.7 \pm 8.3 \mathrm{mV}(n=5)$. The latter effect was also evident in the first AP evoked following current injection, which also had a slower rise time and a more depolarized threshold (Fig. 3A, top). $d V / d t$ plots revealed that TTX reduced both the AIS and somatic $\mathrm{Na}_{\mathrm{V}}$ currents by onethird (Fig. $3 A$ ): AIS peak $d V / d t$ dropped from $38.8 \pm 6.2$ to $23.4 \pm 3.7 \mathrm{~V} / \mathrm{s}$ and somatic peak $d V / d t$ dropped from $94.5 \pm 14.8$ to $59.2 \pm 6.1 \mathrm{~V} / \mathrm{s}(n=4)$. Partial block of AIS and somatic channels also changed the response to current injection. For ex- ample, a $75 \mathrm{pA}$ current injection that induced sustained activity under control conditions induced DP block after $10 \mathrm{~nm}$ TTX (Fig. 3B). A variety of current injections showed that concurrent TTXinduced inhibition of $\mathrm{Na}_{\mathrm{V}}$ channels in the AIS and soma reduced the duration of activity evoked by current injection (Fig. $3 C$ ). Therefore, global partial inhibition of $\mathrm{Na}_{\mathrm{V}}$ channels increases the susceptibility of SN DA neurons to DP block.

\section{Addition of virtual $\mathrm{Na}_{\mathrm{V}}$ channels to the soma delays DP block}

The contribution of somatic $\mathrm{Na}_{\mathrm{V}}$ channels to DP block was then examined by adding virtual $\mathrm{Na}_{\mathrm{V}}$ channels with the dynamic clamp to the soma (i.e., the position of the patch pipette passing current from the dynamic clamp). After $20 \mathrm{~min}$ of $10 \mathrm{~nm}$ TTX application, somatic virtual $\mathrm{Na}_{\mathrm{V}}$ channels altered the first AP evoked by a $75 \mathrm{pA}$ current injection in currentclamped neurons: addition of somatic virtual $\mathrm{Na}_{\mathrm{V}}$ channels increased AP height and the somatic component of the $d V / d t$ plot without changing threshold or the AIS component of the $d V / d t$ plots (Fig. $4 A$ ). In this example, addition of $100 \mathrm{nS}$ of virtual $\mathrm{Na}_{\mathrm{V}}$ conductance nearly replaced the native $\mathrm{Na}_{\mathrm{V}}$ channels blocked by TTX in the soma, but had no effect in the AIS (compare Figs. $3 A, 4 A$ ). Strikingly, this soma-specific manipulation prevented DP block in this neuron (compare Figs. $3 B$, $4 B$ ). The reduction in susceptibility to DP block was evident with a variety of current injections in independent experiments (Fig. 4C). Furthermore, while $100 \mathrm{nS}$ of somatic virtual $\mathrm{Na}_{\mathrm{V}}$ channels delayed DP block, $200 \mathrm{nS}$ prevented DP block. Therefore, the increased sensitivity to DP block produced by pharmacological reduction of $\mathrm{Na}_{\mathrm{V}}$ channel activity in both the soma and AIS is reversed by adding $\mathrm{Na}_{\mathrm{V}}$ channels solely to the soma.

The impact of adding virtual $\mathrm{Na}_{\mathrm{V}}$ channels to the soma was also evident in the absence of TTX and in both adolescent (P14P21) and older (P42) animals. Specifically, when DP block was induced by current injection or addition of virtual NMDARs (Fig. 2), addition of $100 \mathrm{nS}$ of virtual $\mathrm{Na}_{\mathrm{V}}$ channels to the soma delayed DP block, while adding $200 \mathrm{nS}$ of $\mathrm{Na}_{\mathrm{V}}$ channel conductance produced sustained activity (Fig. 5). Therefore, in the absence of pharmacological inhibition and regardless of age, increasing somatic $\mathrm{Na}_{\mathrm{V}}$ channel number is sufficient to diminish susceptibility to DP block.

\section{Somatic virtual anti-Na $\mathrm{a}_{\mathrm{v}}$ channels promote $\mathrm{DP}$ block}

Dynamic clamp can also be used to add virtual anti- $\mathrm{Na}_{V}$ channels to counterbalance the activity of native channels in the soma. In these experiments, native somatic channels respond normally to changes in membrane potential, but their depolarizing currents are nullified by current from virtual anti-channels that gate normally, but produce current that flows in the opposite direction. 
Thus, with this approach, the dynamic clamp produces a net reduction in somatic $\mathrm{Na}_{\mathrm{V}}$ conductance. The spatial specificity of virtual anti- $\mathrm{Na}_{\mathrm{V}}$ channels was apparent from the AP waveform and $d V / d t$ plots (Fig. 6A): only the somatic component was inhibited by the antichannels. Reducing the somatic $\mathrm{Na}_{\mathrm{V}}$ current in this way hastened DP block induced by current injection by $51 \pm 18 \%$ $(n=5)$ and by virtual NMDARs by $40 \pm$ $2.4 \%(n=3)$ (Fig. 6B,C). Together, the responses to virtual $\mathrm{Na}_{V}$ channels and anti- $\mathrm{Na}_{\mathrm{V}}$ channels (Figs. 5, 6) demonstrate that even though APs initiate in the AIS, somatic $\mathrm{Na}_{\mathrm{V}}$ channel density controls the susceptibility to DP block.

\section{Pacemaker rate is proportional to} somatic $\mathrm{Na}_{\mathrm{V}}$ channel density

Having implicated somatic $\mathrm{Na}_{\mathrm{V}}$ channels in DP block, the effects of changing somatic $\mathrm{Na}_{\mathrm{V}}$ channel density on pacemaker activity of SN DA neurons was evaluated by adding virtual $\mathrm{Na}_{\mathrm{V}}$ and anti- $\mathrm{Na}_{\mathrm{V}}$ channels to spontaneously pacemaking neurons. Addition of virtual $\mathrm{Na}_{\mathrm{V}}$ channels at the same levels used to delay DP block resulted in increased pacemaker rate (Fig. $7 A, B$ ), while reducing the somatic $\mathrm{Na}_{V}$ current density with virtual anti- $\mathrm{Na}_{\mathrm{V}}$ channels decreased pacemaker activity (Fig. 7C). Indeed, there was a linear relationship between virtual $\mathrm{Na}_{\mathrm{V}}$ conductance and pacemaker frequency (Fig. 7D). This relationship reflects that virtual $\mathrm{Na}_{\mathrm{V}}$ channels contribute a substantial depolarizing current during the ISI (Fig. 7E). This contribution fits with the activation curve of rat SN DA $\mathrm{Na}_{\mathrm{V}}$ currents (Fig. $1 B$, dotted line), the ISI membrane potential of rat SN DA neurons (Fig. 7E, approximately $-60 \mathrm{mV}$ to $-40 \mathrm{mV}$ ) and the previous demonstration that $\mathrm{Na}_{V}$ current influences pacemaker activity in mouse nigral DA neurons (Puopolo et al., 2007). Thus, somatic $\mathrm{Na}_{\mathrm{V}}$ channels coordinately reduce susceptibility to DP block (Figs. 4-6) and enhance pacemaker frequency (Fig. 7).

Somatic virtual $\mathrm{Na}_{\mathrm{V}}$ channels alone produce abnormally fast pacemaker activity

The marked effects of somatic $\mathrm{Na}_{\mathrm{V}}$ channels in the presence of native AIS and dendritic $\mathrm{Na}_{\mathrm{V}}$ channels raise the question of whether somatic $\mathrm{Na}_{\mathrm{V}}$ channels alone are sufficient for normal $\mathrm{DA}$ neuron pacemaker activity. To address this issue, all native $\mathrm{Na}_{\mathrm{V}}$ channels and APs were blocked with $1 \mu \mathrm{M}$ TTX while currentclamping neurons to $-60 \mathrm{mV}$. Then $2 \mathrm{~s}$ long $50 \mathrm{pA}$ current injections were applied to elicit DP (Fig. 8A). Finally, various levels of virtual $\mathrm{Na}_{\mathrm{V}}$ conductance were added back to the soma with the dynamic clamp (Fig. $8 \mathrm{~A}$, bottom two traces) until the
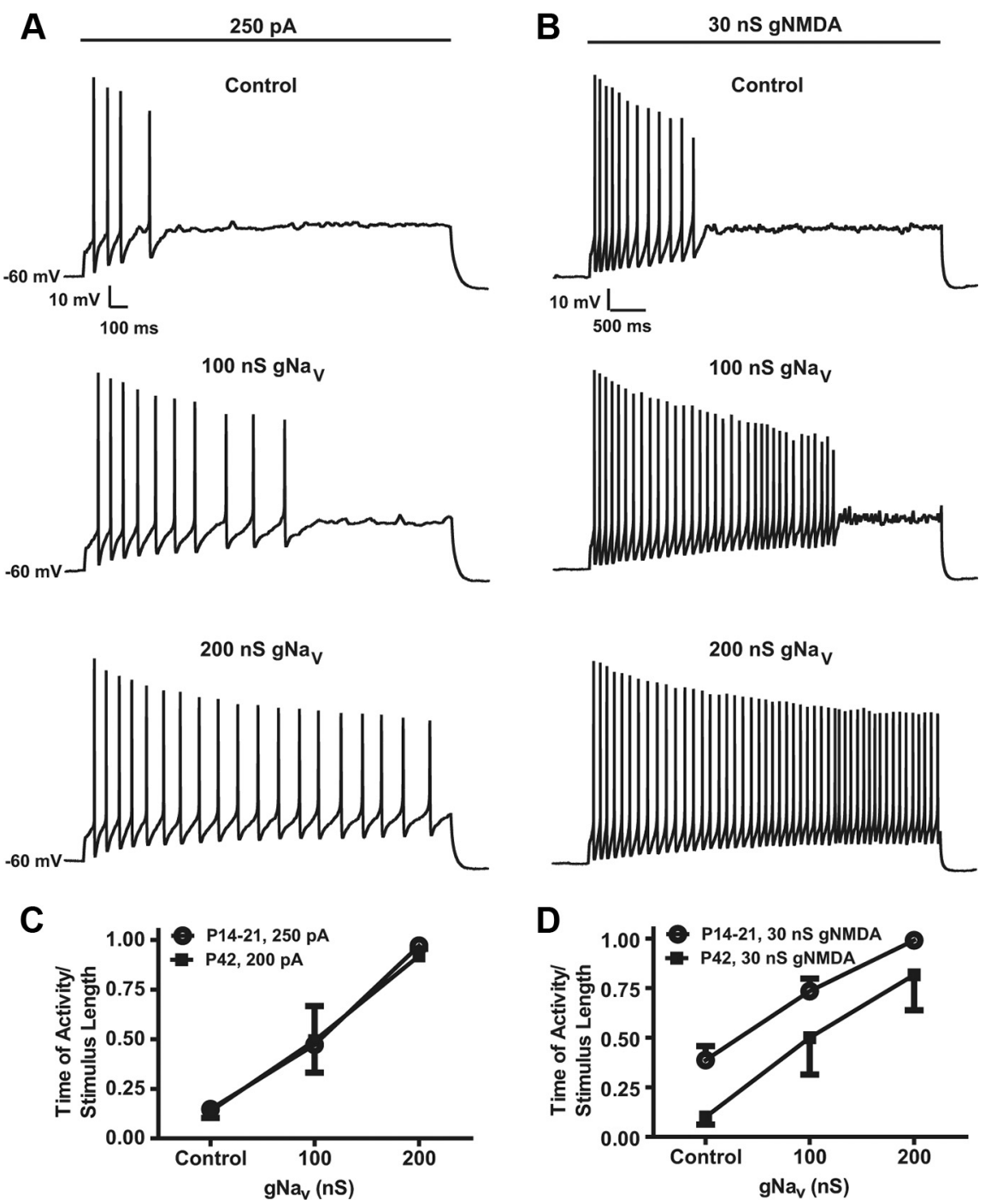

Figure 5. Additional somatic $\mathrm{Na}_{V}$ channels reduce DP block produced by current injection and virtual NMDA conductance in adolescent and older animals. Representative recordings from SN DA neurons current-clamped at $-60 \mathrm{mV}$ followed by $(\boldsymbol{A})$ a $2 \mathrm{~s}$, control conditions (top) and with $100 \mathrm{nS}$ (middle) or $200 \mathrm{nS}$ (bottom) of virtual NaV added via dynamic clamp. Resistance to DP as quantified by length of activity divided by the stimulus length plotted against the virtual $\mathrm{Na}_{V}$ conductance in response to rats (open circles; $n=11$ ) and $200 \mathrm{pA}$ current injection to SN DA neuron in slices from a P42 rat (black square; $n=3$ ). NMDA conductance ( $30 \mathrm{nS}$ ) was used to stimulate SN DA neurons in slices from P14-P21 (open circles; $n=12$ ) and P42 (black squares; $n=3$ ) rats. Symbols and error bars indicate the mean \pm SEM.

height of the first AP (measured from peak to trough of AHP) began to approach control levels (Fig. 8A,B).

With the production of large APs, repetitive spiking was evoked with $\mathrm{Na}_{\mathrm{V}}$ channels only in the soma (Fig. 8A,D). However, this activity was abnormally fast; for example, $800 \mathrm{nS}$ of virtual $\mathrm{Na}_{\mathrm{V}}$ conductance, which produced APs that were $\sim 80 \%$ of the control height (Fig. $8 B$ ), resulted in pacemaker-like activity that was $\sim 3$-fold faster than that of the native distributed channel (Fig. 8C). Furthermore, somatic virtual channels reconstituted true pacemaker activity (i.e., repetitive spiking without added bias current injection), but spiking frequency was again higher than normal (Fig. $8 D ; n=11$ ). The production of abnormally high pacemaker rates by somatic restriction of $\mathrm{Na}_{\mathrm{V}}$ channels implies that the widespread distribution of $\mathrm{Na}_{\mathrm{V}}$ channels in the somatodendritic compartment of SN DA neurons is critical for the production of native slow pacemaker activity. 


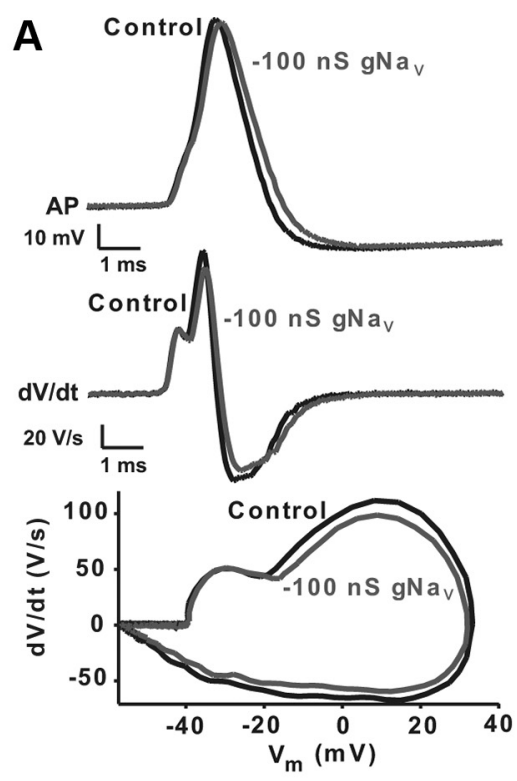

B

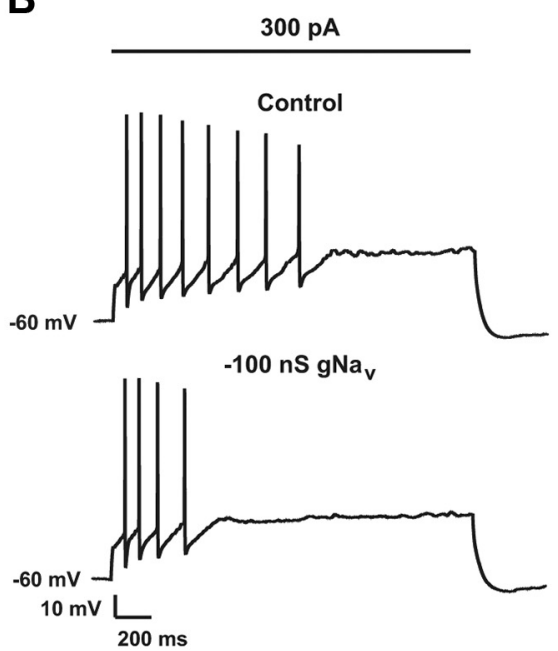

C
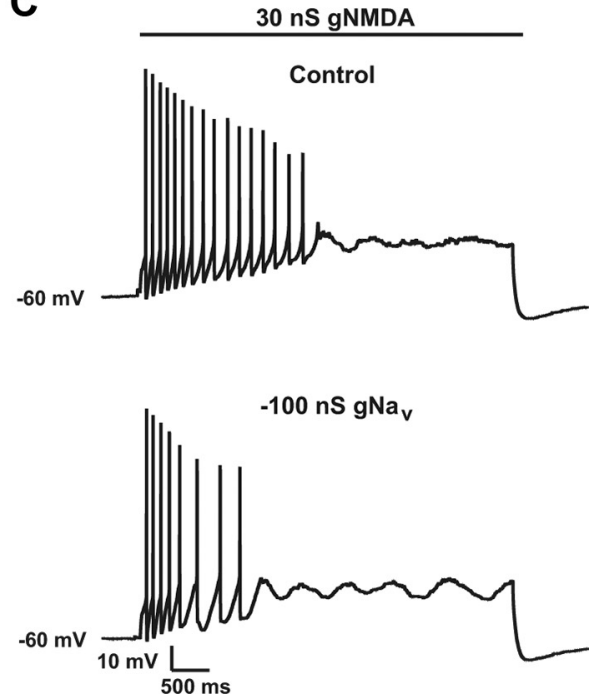

Figure 6. Addition of virtual anti-Na $\mathrm{N}_{\mathrm{V}}$ channels to the soma hastens DP block. The dynamic clamp technique was used to add $100 \mathrm{nS}$ of virtual anti- $\mathrm{Na}_{V}$ conductance to the soma of an $\mathrm{SN}$ DA neuron while being current-clamped to $-60 \mathrm{mV}$ followed by a 250 or $300 \mathrm{pA}$ current step or
Explaining the effect of somatic current isolation with simulations

Somatodendritic $\mathrm{Na}_{\mathrm{V}}$ channel distribution was manipulated in a compartmental SN DA neuron model to investigate the mechanism by which somatic isolation of $\mathrm{Na}_{\mathrm{V}}$ channels results in an abnormally high pacemaker frequency. As noted (see Materials and Methods), the following analysis was not affected by the presence of an axon, AIS, or calcium-activated SK potassium channels. Somatic and dendritic current-clamp recordings (Fig. 1C) were simulated with $\mathrm{Na}_{\mathrm{V}}$ channels both evenly distributed throughout the somatic and dendritic compartments and isolated to the soma only. In this way, simulation mimicked control pre-TTX slice recordings and post-TTX dynamic clamp slice recordings. When $\mathrm{Na}_{\mathrm{V}}$ channels were distributed (Fig. 9A, left), full height APs were produced in both compartments with a slow frequency similar to that observed under similar somatic recording conditions in control slice recordings (Fig. $8 \mathrm{~A}$, top trace). However, simulating the dynamic clamp protocol by injecting $\mathrm{Na}_{V}$ currents into the soma resulted in a threefold increase in somatic spiking frequency when compared with the distributed channel (Fig. 9A, top). Furthermore, simulated dendritic recordings revealed that the full height dendritic APs observed with distributed $\mathrm{Na}_{\mathrm{V}}$ channels were replaced by short, broad spikelets when the channels were isolated to the soma (Fig. 9A, bottom). These simulations suggest that the dendrites are essentially passive in the absence of local $\mathrm{Na}_{\mathrm{v}}$ channels and become a current sink due to the necessity to charge the capacitive load of the dendritic membrane (Fig. 9B,C). An imbalance between local $\mathrm{Na}_{\mathrm{V}}$ and $\mathrm{K}_{\mathrm{V}}$ currents then results in excess subthreshold current during the ISI, which in turn produces faster DP of the somatic and proximal membranes leading to faster pacing (compare Figs. $1 C$, middle, $9 C)$.

\section{Simulation predictions for effects of manipulating $\mathrm{Na}_{\mathrm{v}}$ gating properties}

If the model captures the true behavior of DA neurons, then it should also predict experimental responses to changes in virtual channel gating. One way to reduce local current could be to modify voltage-dependent gating to decrease the window current that tonically flows within a range of membrane potentials where steady-state activation and inactivation overlap (Fig. $1 \mathrm{~B}$, hatched area). Therefore, with soma-confined $\mathrm{Na}_{\mathrm{V}}$ channels, three changes to $\mathrm{Na}_{V}$ gating parameters (Fig. $10 \mathrm{~A}$ ) were examined in the compartmental SN DA neuron model. First, to decrease the overall window current the activation curve $\left(m_{\infty}{ }^{3}\right)$ was shifted 5 $\mathrm{mV}$ to the right and the inactivation curve $\left(h_{\infty}\right)$ was shifted $5 \mathrm{mV}$ to the left (Fig. 10A; $m / h$ shift). Even though more conductance was needed to produce normal height APs (3900 nS vs $800 \mathrm{nS}$ ), when the $m / h$ shifted channel was substituted in the model the simulated firing frequency was slower (Fig. $10 \mathrm{~B} ; 3 \mathrm{~Hz}$ with $\mathrm{m} / \mathrm{h}$ shift vs $5.5 \mathrm{~Hz}$ with $\mathrm{Na}_{\mathrm{V}}$ ). Then, to isolate which gating parameter reduced the firing frequency, each parameter was shifted separately. Shifting only the activation curve $5 \mathrm{mV}$ to the right (Fig. $10 \mathrm{~A} ; \mathrm{m}$ shift) also required more conductance to produce normal height APs than native $\mathrm{Na}_{\mathrm{V}}$ and decreased spiking frequency (Fig.

$\leftarrow$

$30 \mathrm{nS}$ virtual NMDA conductance. $\boldsymbol{A}$, Representative traces of the first AP evoked by $250 \mathrm{pA}$ current injection (top) under control conditions (control) and $100 \mathrm{nS}$ of virtual anti-Na $\mathrm{V}_{\mathrm{V}}$ channel conductance $(-100 \mathrm{nS} \mathrm{gNa}$ ) and their corresponding $d V / d t$ (middle) and phase plane (bottom) plots. Representative current-clamp recordings in response to $(\boldsymbol{B})$ a $300 \mathrm{pA}$ current injection and $(C) 30 \mathrm{nS}$ of virtual NMDA conductance under control conditions (control) and in the presence of $100 \mathrm{nS}$ virtual anti-Na $\mathrm{N}_{\mathrm{V}}$ channel conductance $\left(-100 \mathrm{nS} \mathrm{gNa}_{\mathrm{V}}\right.$ ). 

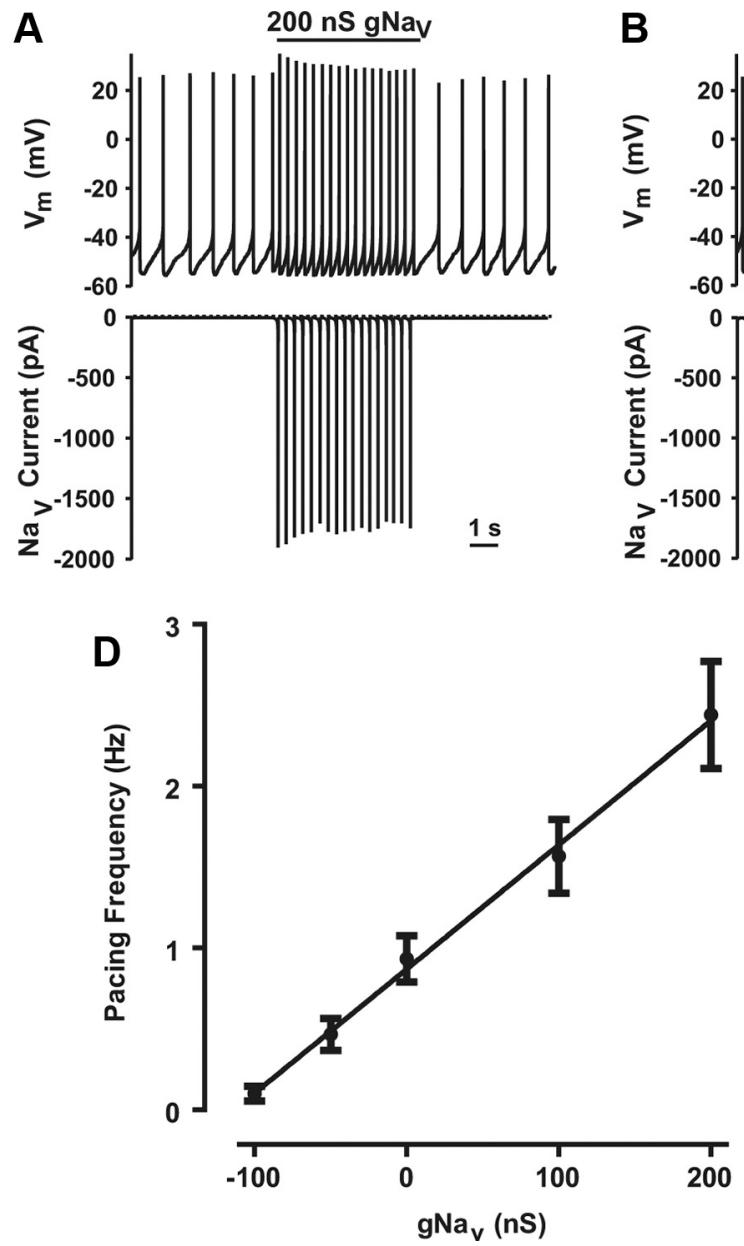

B

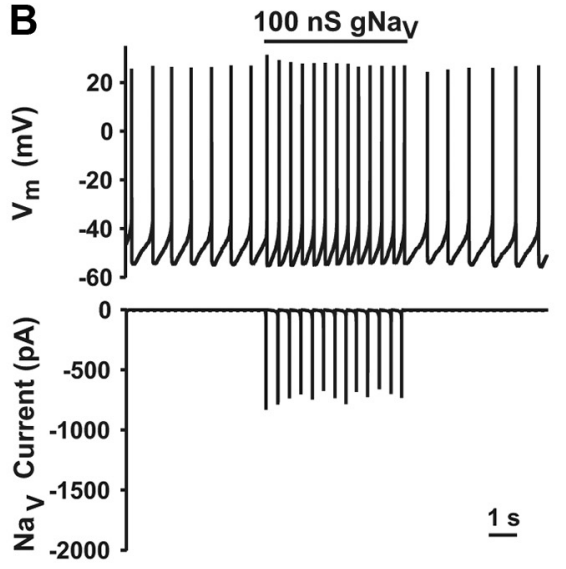

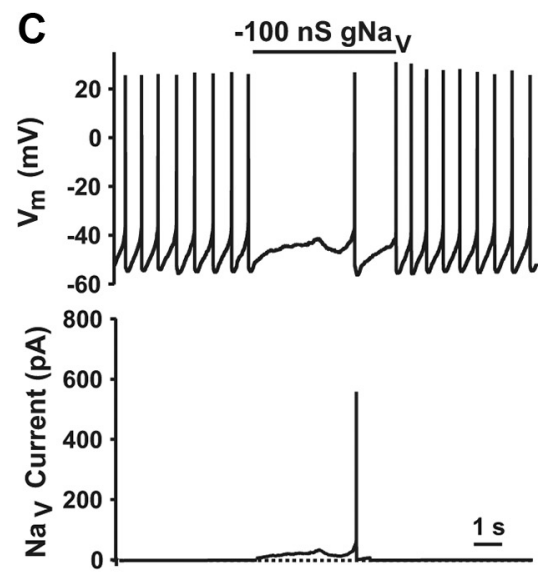

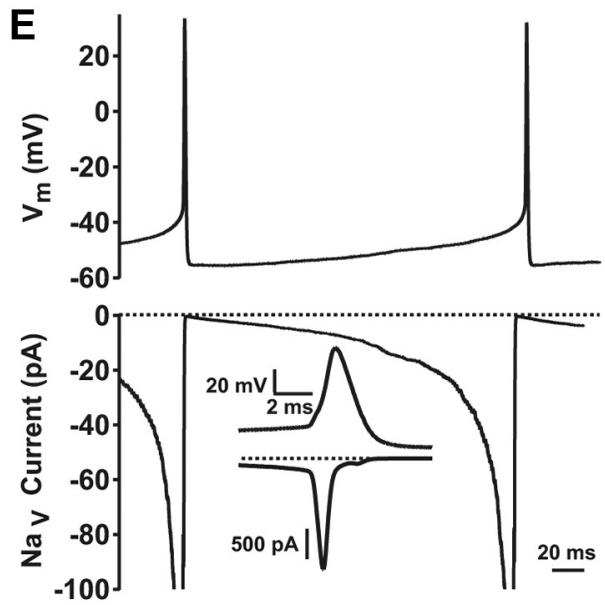

Figure 7. $\mathrm{Na}_{v}$ current regulates the slow pacemaker rate of SN DA neurons. Representative current-clamp recordings (A-C, top) from freely pacing SN DA neurons to which (A) 200, (B) 100 , and $(\boldsymbol{C})-100 \mathrm{nS}$ of virtual $\mathrm{Na}_{\mathrm{v}}$ conductance have been added using dynamic clamp. The bottom graphs of $\boldsymbol{A}-\boldsymbol{C}$ indicate the dynamic clamp current. $\boldsymbol{D}$, Linear regression of the pacing frequency in response to different virtual $\mathrm{Na}_{\mathrm{V}}$ conductance levels. $\boldsymbol{E}$, Second and third $\mathrm{AP}$ (top) and corresponding virtual $\mathrm{Na}_{\mathrm{V}}$ current (bottom) during the $200 \mathrm{nS}$ gNa $\mathrm{V}_{\mathrm{V}}$ application (A) to illustrate the additional $\mathrm{Na}_{\mathrm{V}}$ current added during the ISI.

$10 \mathrm{~B} ; 2900 \mathrm{nS} ; 3 \mathrm{~Hz}$ ). However, shifting only the inactivation curve $5 \mathrm{mV}$ to the left (Fig. $10 \mathrm{~A}$; $h$ shift) produced normal height APs with only a small increase in conductance ( $1100 \mathrm{nS}$ vs $800 \mathrm{nS}$ ) and no change in spiking frequency (Fig. $10 \mathrm{~B} ; 5.5 \mathrm{~Hz}$ ). Therefore, these simulations predict that only shifts in activation gating would normalize the spiking frequency when all $\mathrm{Na}_{\mathrm{V}}$ current is confined to the soma.

\section{Experiments conform to the model's predictions about channel activation}

The model-generated hypothesis that high spiking frequency is induced by somatic channels as a consequence of excess somatic and proximal $\mathrm{Na}_{\mathrm{V}}$ current was tested by replacing native $\mathrm{Na}_{\mathrm{V}}$ currents blocked by $1 \mu \mathrm{M}$ TTX with virtual $\mathrm{Na}_{\mathrm{V}}$ channels that had altered gating parameters (i.e., as modeled above). The response to $50 \mathrm{pA}$ current injections in neurons current-clamped at -60 $\mathrm{mV}$ was then determined. For each modified virtual channel, conductance levels were adjusted to produce AP height that was at least $80 \%$ of the control (Fig. $11 \mathrm{~B}$ ). Under these conditions, $\mathrm{m} / \mathrm{h}$ shift and $m$ shift models produced lower spiking frequencies (Fig. $11 A, C$ ). However, the $h$ shift model, like the unmodified virtual channel, produced abnormally fast activity (Fig. 11A,C). Therefore, as predicted by modeling (Fig. 10), only manipulations that reduced subthreshold $\mathrm{Na}_{\mathrm{V}}$ by shifting activation pro- duced slower spiking when limited to the soma (Fig. 11A,C). This result shows that subthreshold $\mathrm{Na}_{\mathrm{v}}$ current is important in regulating the pacing frequency in DA neurons.

\section{Pacemaker frequency and somatodendritic $\mathrm{Na}_{\mathrm{V}}$ channel distribution}

The experiments thus far examined the effect of changing $\mathrm{Na}_{\mathrm{V}}$ channel density in the soma and eliminating $\mathrm{Na}_{\mathrm{V}}$ channels in dendrites. However, because DA neurons possess multiple dendrites, it is not possible to alter $\mathrm{Na}_{\mathrm{V}}$ channel density uniformly and simultaneously throughout the dendritic compartment with the dynamic clamp. However, the above analysis demonstrated the predictive power of modeling, in which it is possible to control compartmental channel distribution. Therefore, simulations were used to vary the balance of somatic and dendritic $\mathrm{Na}_{\mathrm{V}}$ channels to understand how distribution affects spiking frequency in DA neurons. Specifically, recordings of responses to $80 \mathrm{pA}$ injections into the soma of neurons current-clamped to $-60 \mathrm{mV}$ were simulated with varying distributions of $\mathrm{Na}_{\mathrm{V}}$ channels in the soma and dendrites while keeping the total across both compartments a constant. Strikingly, as $\mathrm{gNa}_{\mathrm{V}}$ is moved from the soma to the dendrites, spiking frequency decreases (Fig. 12A,B). The plot of frequency dependence in Figure $12 B$ shows that the uni- 
A

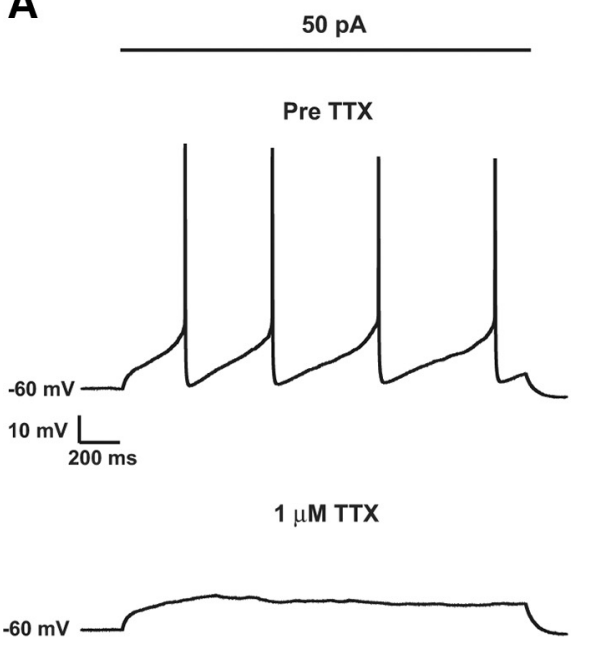

$1 \mu \mathrm{M} \mathrm{TTX}+600 \mathrm{nS} \mathrm{gNa}$

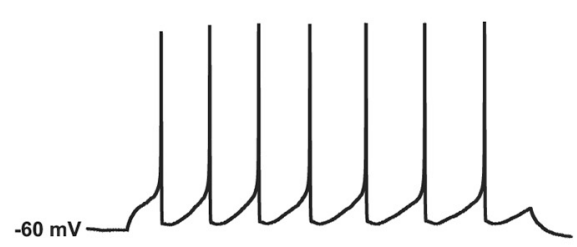

$1 \mu \mathrm{M} \mathrm{TTX}+800 \mathrm{nS} \mathrm{gNa}_{\mathrm{v}}$

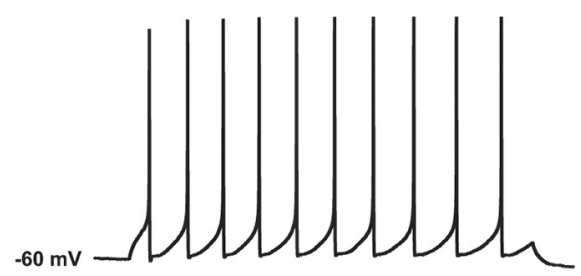

B
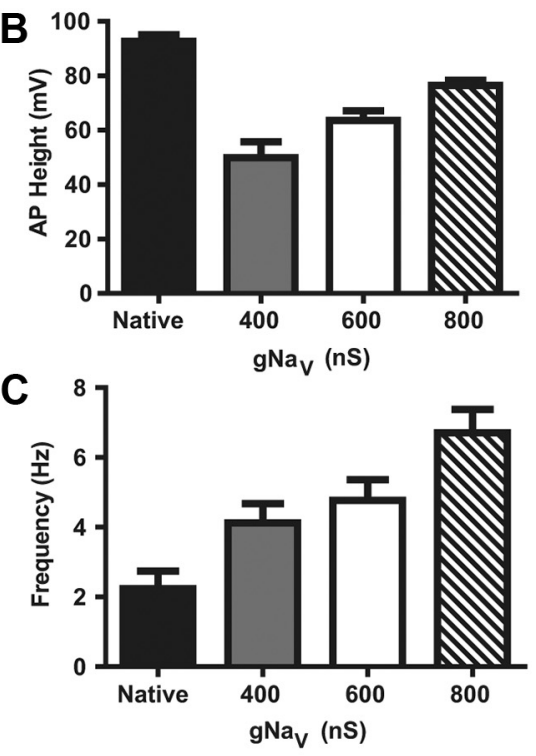

D
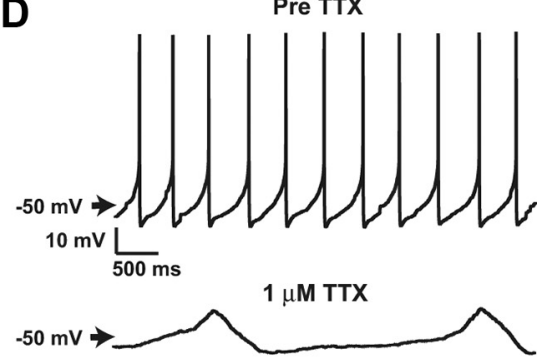

$1 \mu \mathrm{M}$ TTX $+800 \mathrm{nS} \mathrm{gNa}$

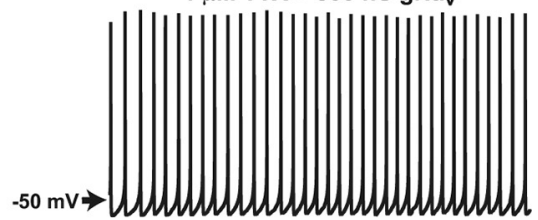

Figure 8. Replacing the distributed native $\mathrm{Na}_{V}$ current with virtual $\mathrm{Na}_{V}$ current reconstitutes pacing, but at a higher frequency. $A$, Representative SN DA neuron current-clamp recording held at $-60 \mathrm{mV}$ followed by a $2 \mathrm{~s}$ long, $50 \mathrm{pA}$ current injection before (pre-TTX; top trace) and after maximal block of TTX-sensitive sodium channels with $1 \mu \mathrm{M}$ TTX (second trace) followed by application of $600 \mathrm{nS}$ (third trace) and $800 \mathrm{nS}$ (fourth trace) of virtual $\mathrm{Na}_{\mathrm{V}}$ conductance to the soma. B, AP height and (C) pacing frequency before TTXapplication (Native) and after $10 \mathrm{~min}$ of $1 \mu \mathrm{M}$ TTX application with different levels of virtual $\mathrm{Na}_{\mathrm{y}}$ conductance. Error bars indicate the mean and SEM of 3-9 cells. $\boldsymbol{D}$, Representative current-clamp recordings from a freely pacing neuron before and after $1 \mu \mathrm{m}$ TTX followed by reconstitution of pacing with $800 \mathrm{nS}$ of virtual $\mathrm{Na}_{\mathrm{V}}$ conductance.

form distribution found in native DA neurons produces a minimal pacemaker rate, while preserving somatic channels. In SN DA neurons, the preservation of somatic channels is critical for reliable backpropagation of APs through the soma into other nonaxon-baring dendrites and concomitant release of DA.

Modeling was also used to determine the effect of adding $\mathrm{gNa}_{\mathrm{V}}$ to different compartments in neurons with an initially uniform distribution of $\mathrm{Na}_{\mathrm{V}}$ channels (i.e., as found in native neurons). Strikingly, although the dendritic compartment is far larger than the soma, adding extra channels to the soma alone is as effective in increasing pacemaker frequency as distributing the extra channels throughout the dendrites or the whole somatodendritic compartment (Fig. 12C). This finding further emphasizes the critical role of $\mathrm{Na}_{\mathrm{V}}$ channels in nigral $\mathrm{DA}$ neuron pacemaker frequency.

\section{Discussion}

$\mathrm{Na}_{\mathrm{V}}$ channels of SN DA neurons are known to be responsible for AP initiation in the AIS and propagation throughout the axonal, somatic and dendritic compartments. Although it has been suggested that $\mathrm{Na}_{\mathrm{V}}$ channel inactivation and density contribute to the susceptibility of DA neurons to DP block (Kuznetsova et al., 2010), a phenomenon that correlates with antipsychotic drug efficacy (Chiodo and Bunney, 1983; White and Wang, 1983a,b; Grace and Bunney, 1986; Esposito and Bunney, 1989; Skarsfeldt and Perregaard, 1990; Skarsfeldt, 1992; Valenti et al., 2011), this hypothesis has not been confirmed directly in neurons. Furthermore, it has also been unclear whether $\mathrm{Na}_{\mathrm{V}}$ channels in the soma play a role in controlling DA neuron pacemaker activity and DP block. Indeed, one might conclude that somatic channels are not critical because APs that initiate in the AIS coming off of a dendrite sometimes fail to backpropagate through the soma (Gentet and Williams, 2007) even though isolated somata can pace autonomously (Kita et al., 1986; Hainsworth et al., 1991). In this study, dynamic clamp was used to show that, even though APs initiate in the AIS, somatic $\mathrm{Na}_{\mathrm{V}}$ channels contribute to pacemaker frequency and susceptibility to DP block. It was also shown that limiting $\mathrm{Na}_{\mathrm{V}}$ channels to the soma is sufficient for pacemaker activity, but this produces abnormally high frequencies due to excessive local subthreshold $\mathrm{Na}_{\mathrm{V}}$ current. Although not confirmed by direct measurement of dendritic voltage, these results together with computational modeling provide evidence that the slow pacemaker frequency that characterizes SN DA neurons is supported by the wide distribution of $\mathrm{Na}_{\mathrm{V}}$ channels in the somatodendritic compartment. A secondary consequence of low $\mathrm{Na}_{\mathrm{V}}$ channel density, compared with fast pacing neurons, is that SN DA neurons are susceptible to DP block. Thus, two seemingly separate characteristics, low-frequency pacemaker activity and susceptibility to DP block, are causally linked to $\mathrm{Na}_{\mathrm{V}}$ channel density and localization in SN DA neurons.

This $\mathrm{Na}_{\mathrm{V}}$ channel balancing act between firing frequency and DP block susceptibility may be a general principle. If this is the case, then neurons with high $\mathrm{Na}_{\mathrm{V}}$ channel densities should exhibit high firing frequencies and a reduced sensitivity to DP block. In fact, this is observed in GABA neurons of the SN pars reticulata. These neurons express a similar complement of $\mathrm{Na}_{\mathrm{V}}$ channel pore forming $\alpha$-subunits and auxiliary $\beta$-subunits as DA neurons, but have a higher $\mathrm{Na}_{\mathrm{V}}$ channel density and produce faster pacemaker activity (Seutin and Engel, 2010; Ding et al., 2011). These cells are also relatively more resistant to DP block than SN DA neurons (Richards et al., 1997). Thus, $\mathrm{Na}_{\mathrm{V}}$ channels 
may influence both pacemaker frequency and susceptibility to DP block in a variety of neurons.

An alternative case of somatodendritic $\mathrm{Na}_{\mathrm{V}}$ density, distribution, and gating occurs in serotonergic (5-HT) medullary raphé (MR) neurons, which exhibit slow pacemaker activity (Wang and Richerson, 1999) with broad APs (Zhang et al., 2006) like SN DA neurons. Both DA and 5-HT neurons produce somatodendritic neurotransmitter release, but with different mechanisms resulting in the necessity for differential channel distribution and density. In SN DA neurons, APs backpropagate into the distal dendrites with very little decrement resulting in $\mathrm{Na}_{\mathrm{V}}$ channel-dependent dendritic release of DA (Santiago et al., 1992; Häusser et al., 1995). However, in 5-HT neurons in the dorsal raphé nucleus, dendritic activity-dependent calcium signals decrement with distance from the soma (de Kock et al., 2006) and release of 5-HT from dendrites (unlike from the soma) is AP independent (L. Colgan and E. Levitan, personal communication). Furthermore, consistent with our analysis and the more limited contribution of dendritic $\mathrm{Na}_{\mathrm{V}}$ channels in 5-HT neurons, pacemaker activity was reconstituted with somatic virtual $\mathrm{Na}_{\mathrm{V}}$ channels in 5-HT MR neurons, but no gating adjustment was needed to achieve the slow pacemaker rate (Milescu et al., 2010). Therefore, it is likely that 5-HT MR neurons have few dendritic $\mathrm{Na}_{\mathrm{V}}$ channels relative to the soma, thus producing different somatodendritic excitability and release than found with DA neurons.

In DA neurons, the slow pacemaker activity that results from low $\mathrm{Na}_{\mathrm{V}}$ channel density and broad somatodendritic distribution may be of importance for sensitivity to behaviorally relevant stimuli. DA neuron intrinsic pacemaker activity contributes to setting the dopaminergic tone of target brain regions. Synaptic activity modifies the intrinsic pacemaker activity of SN DA neurons to produce behaviorally relevant regular, irregular, and bursting patterns of activity (Hyland et al., 2002). Burst firing results in a larger DA release than baseline activity (Heien and Wightman, 2006). It is this differential DA release that indicates the potential reward value of a particular stimulus (for review, see Hauber, 2010). Putzier et al. (2009b) showed that the response of SN DA neurons to both inhibitory and stimulatory synaptic input depends exponentially on the baseline ISI of the neuron (i.e., the slower the baseline frequency the larger the potential response). Therefore, if so-
A

A $\underset{\text { Distributed }}{\mathrm{gNa}_{\mathrm{V}}}$

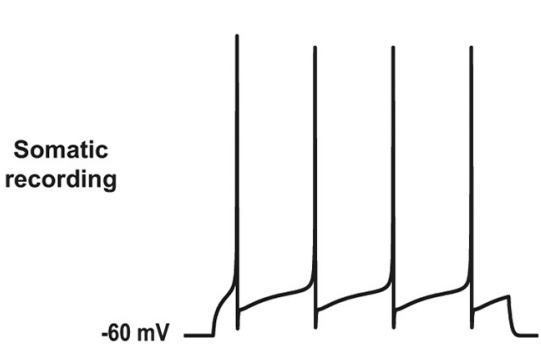

Dendritic
recording

B
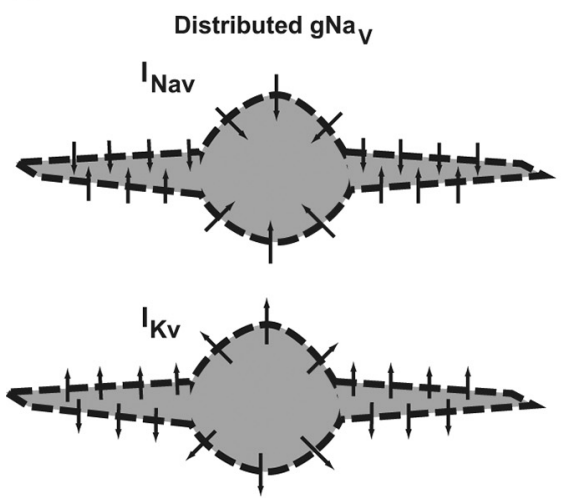

Soma Only

$\mathrm{gNa}_{\mathrm{V}}$
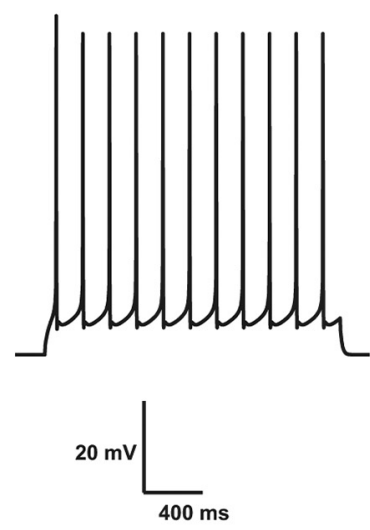

C

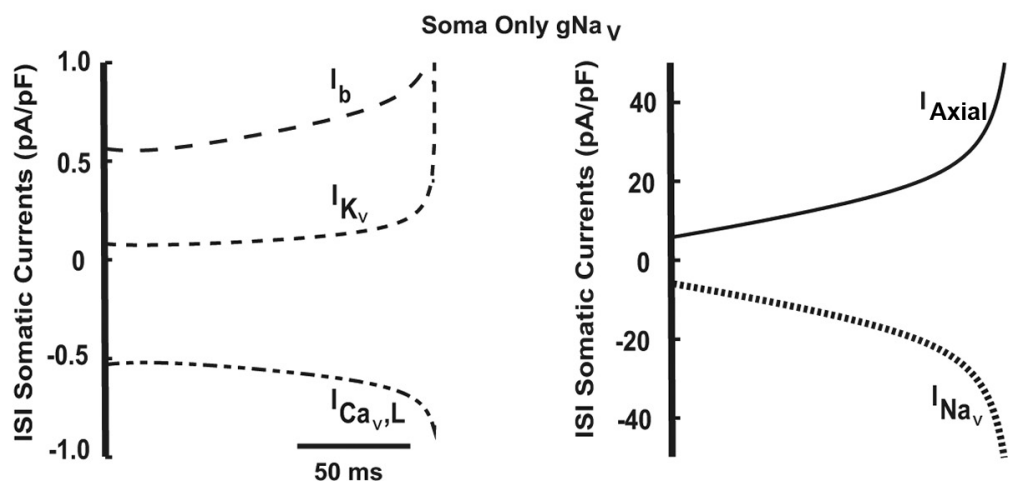

Figure 9. Somatic isolation of $\mathrm{Na}_{\mathrm{V}}$ current results in abnormally fast pacing in an SN DA neuron compartmental model. The simulation paralleled the experimental protocol shown in Figure 7. $A$, Simulated voltage traces with distributed and somatically isolated $\mathrm{Na}_{\mathrm{V}}$ in response to an $80 \mathrm{pA}$ applied current pulse measured from the soma and dendrite. $\boldsymbol{B}$, Diagram of $\mathrm{Na}_{V}$ currents flowing in a simplified somatodendritic compartment with $\mathrm{Na}_{v}$ channels distributed (left) or in the soma only (right). When $\mathrm{Na}_{v}$ channels are distributed, Nav currents can uniformly activate Kv channels resulting in little axial current flow (left). When all of the $\mathrm{gNaV}$ is in the soma, the sodium current spreads axially, depolarizing the distal regions much less than the proximal regions, resulting in a proximal to distal Kv current gradient. Large arrows indicate axial current sink. C, Somatic currents flowing during the ISI of spikes 6 and 7 in the Soma Only gNa $a_{V}$ condition in $A . I_{K V}=$ composite voltage-gated potassium currents, $I_{b}=$ sum of constitutively active GIRK current and sodium leak current, $I_{\mathrm{Cav}, \mathrm{L}}=\mathrm{L}$-type calcium current, $I_{\text {Nav }}=$ TTX-sensitive voltage-gated sodium current, and $I_{\text {Axial }}=$ axial current. $I_{\text {Axial }}$ and $I_{\text {Nav }}$ have been plotted separately on the right graph with an expanded $y$-axis scale. For comparison, see the middle panel of Figure 1 C for the ISI somatic currents flowing during the distributed $g \mathrm{Na}_{v}$ condition. 

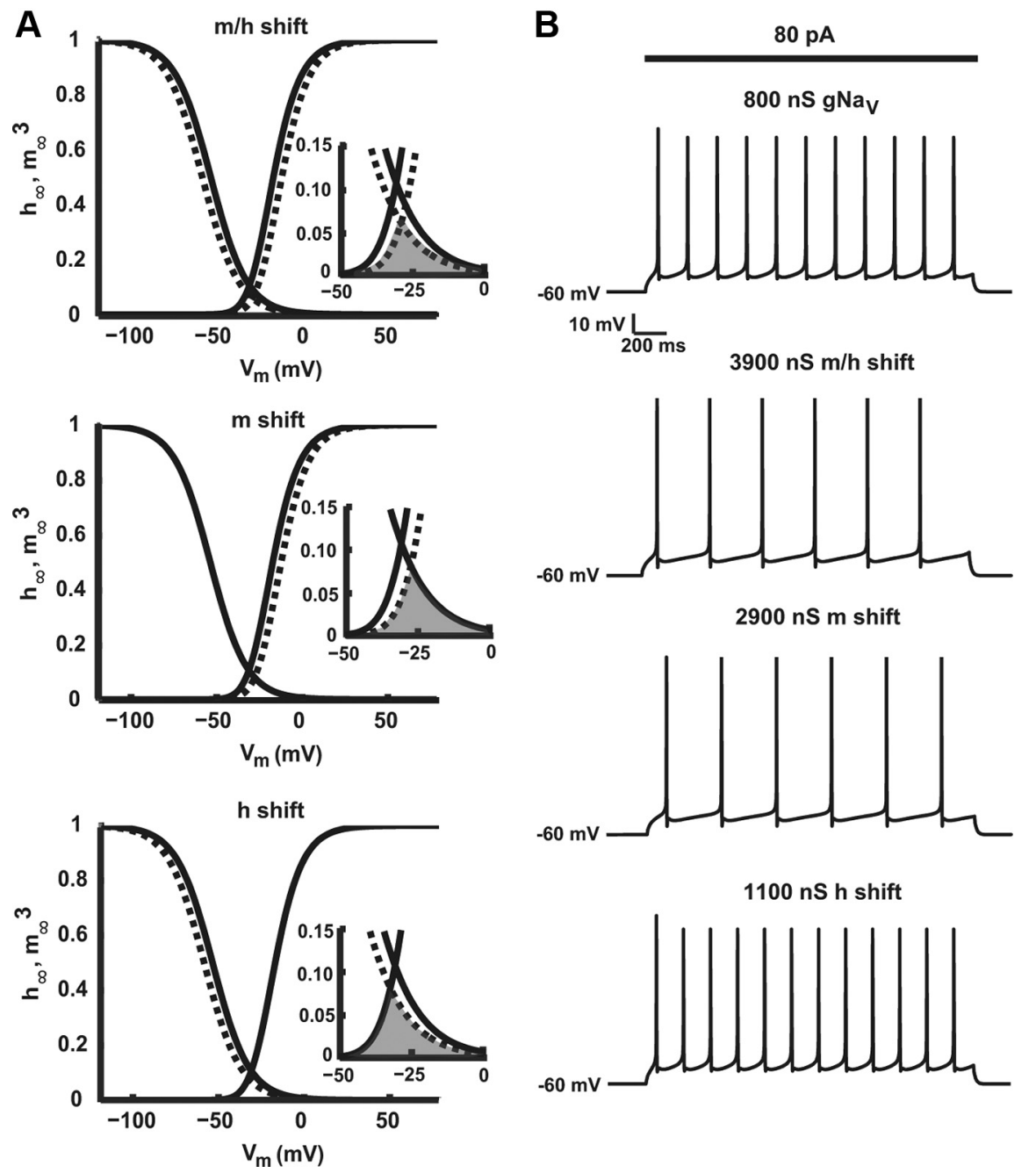

2900 nS m shift

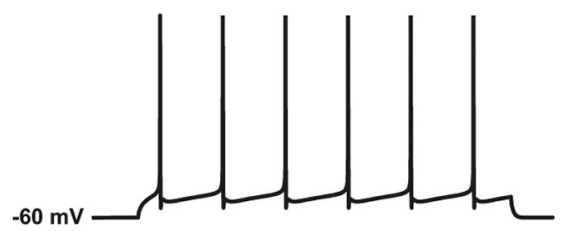

$1100 \mathrm{nS}$ h shift

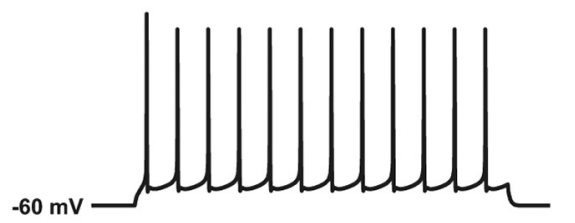

Figure 10. Simulations predict effects of $\mathrm{Na}_{\mathrm{v}}$ window current manipulations on spiking frequency. $A$, Steady-state inactivation and activation curves of the model $\mathrm{Na}_{\mathrm{V}}$ current (solid lines in each graph), a $5 \mathrm{mV}$ right shift in the activation curve and a $5 \mathrm{mV} \mathrm{left}$ shift in the inactivation curve $(\mathrm{m} / \mathrm{h}$ shift; dotted lines; top), a $5 \mathrm{mV}$ right shift in the activation curve only ( $m$ shift; dotted line; middle), and a $5 \mathrm{mV}$ left shift in the inactivation curve ( $h$ shift; dotted line; bottom) used in both dynamic clamp and modeling experiments. Shaded area of each inset indicates the resulting window current for each manipulation. $B$, Simulated activity of a model SN DA neuron held at $-60 \mathrm{mV}$ and stimulated with a $2 \mathrm{~s}, 80 \mathrm{pA}$ current injection with somatically isolated $\mathrm{Na}_{\mathrm{V}}$ current with the indicated gating shifts.

matodendritic balance of $\mathrm{Na}_{\mathrm{V}}$ current were modified, the resulting change in of baseline frequency could reduce the potential responsiveness of the neuron to synaptic input.

$\mathrm{Na}_{\mathrm{V}}$ channel current kinetics, expression, and targeting are endogenously modulated by transcriptional and posttranslational modifications, protein-protein interactions, and differences in $\mathrm{Na}_{\mathrm{V}} \alpha$ - and $\beta$-subunit composition (Diss et al., 2004; Shao et al., 2009). These changes can occur acutely, within seconds to minutes in the case of phosphorylation events, or chronically, within hours to days as with protein expression and changes in trafficking. Therefore, these mechanisms for regulating somatic $\mathrm{Na}_{\mathrm{V}}$ channels have the potential to modulate SN DA neuronal pacemaker frequency and thus sensitivity to synaptic input.

Somatic $\mathrm{Na}_{\mathrm{V}}$ channel modulation may also have the potential to affect the neuroleptic effects and extrapyramidal side effects of some antipsychotic drugs. The clinical efficacy and side effects of chronic antipsychotic drug treatment have been correlated with DP block of midbrain DA neurons recorded in chronically treated anesthetized animals (Chiodo and Bunney, 1983; White and Wang, 1983a,b; Grace and Bunney, 1986; Esposito and Bunney, 1989; Skarsfeldt and Perregaard, 1990; Skarsfeldt, 1992; Valenti et al., 2011). Recently, antipsychotic drugs were shown to accumulate in neurons and be released to inhibit $\mathrm{Na}_{\mathrm{V}}$ channels (Tischbirek et al., 2012). The results presented here suggest that this inhibition could, by reducing somatic $\mathrm{Na}_{\mathrm{V}}$ channel activity, contribute to DP block and hence the efficacy of antipsychotic drugs.

In conclusion, the proper distribution and density of $\mathrm{Na}_{\mathrm{V}}$ channels throughout the soma and dendrites of SN DA neurons is necessary for the hallmark slow pacemaker rate, which allows for optimal differential DA release upon synaptic stimulation of SN DA neurons. Furthermore, the low somatic $\mathrm{Na}_{\mathrm{V}}$ channel density responsible for the characteristic slow pacemaker activity of SN DA neurons is also responsible for their susceptibility to DP block, a characteristic of DA neurons linked to the efficacy of antipsychotic drugs. The balance of $\mathrm{Na}_{\mathrm{V}}$ channels required for optimal pacemaker frequency and sensitivity to DP block can be tipped by changing the $\mathrm{Na}_{\mathrm{V}}$ current density, distribution, or gating, which could result in altered signal transmission and antipsychotic drug efficacy.

\section{References}

Bettencourt JC, Lillis KP, Stupin LR, White JA (2008) Effects of imperfect dynamic clamp: Computational and experimental results. J Neurosci Methods 169:282-289.

Blythe SN, Wokosin D, Atherton JF, Bevan MD (2009) Cellular mechanisms underlying burst firing in substantia nigra dopamine neurons. J Neurosci 29:15531-15541.

Bradaia A, Trube G, Stalder H, Norcross RD, Ozmen L, Wettstein JG, Pinard A, Buchy D, Gassmann M, Hoener MC, Bettler B (2009) The selective antagonist EPPTB reveals TAAR1-mediated regulatory mechanisms in dopaminergic neurons of the mesolimbic system. Proc Natl Acad Sci U S A 106: 20081-20086.

Chan CS, Guzman JN, Ilijic E, Mercer JN, Rick C, Tkatch T, Meredith GE, Surmeier DJ (2007) 'Rejuvenation' protects neurons in mouse models of Parkinson's disease. Nature 447:1081-1086.

Chiodo LA, Bunney BS (1983) Typical and atypical neuroleptics: differential effects of chronic administration on the activity of A9 and A10 midbrain dopaminergic neurons. J Neurosci 3:1607-1619.

Deister CA, Teagarden MA, Wilson CJ, Paladini CA (2009) An intrinsic neuronal oscillator underlies dopaminergic neuron bursting. J Neurosci 29:15888-15897.

de Kock CP, Cornelisse LN, Burnashev N, Lodder JC, Timmerman AJ, Couey JJ, Mansvelder HD, Brussaard AB (2006) NMDA receptors trigger neurosecretion of 5-HT within dorsal raphe nucleus of the rat in the absence of action potential firing. J Physiol 577:891-905.

Ding S, Matta SG, Zhou FM (2011) Kv3-like potassium channels are required for sustained high-frequency firing in basal ganglia output neurons. J Neurophysiol 105:554-570.

Diss JK, Fraser SP, Djamgoz MB (2004) Voltage-gated $\mathrm{Na}^{+}$channels: Mul- 
tiplicity of expression, plasticity, functional implications and pathophysiological aspects. Eur Biophys J 33:180-193.

Durante P, Cardenas CG, Whittaker JA, Kitai ST, Scroggs RS (2004) Low-threshold L-type calcium channels in rat dopamine neurons. J Neurophysiol 91:1450-1454.

Esposito E, Bunney BS (1989) The effect of acute and chronic treatment with SCH 23390 on the spontaneous activity of midbrain dopamine neurons. Eur J Pharmacol 162:109-113.

Gentet LJ, Williams SR (2007) Dopamine gates action potential backpropagation in midbrain dopaminergic neurons. J Neurosci 27:1892-1901.

Grace AA, Bunney BS (1983a) Intracellular and extracellular electrophysiology of nigral dopaminergic neurons-1. Identification and characterization. Neuroscience 10: 301-315.

Grace AA, Bunney BS (1983b) Intracellular and extracellular electrophysiology of nigral dopaminergic neurons-2. Action potential generating mechanisms and morphological correlates. Neuroscience 10:317-331.

Grace AA, Bunney BS (1986) Induction of depolarization block in midbrain dopamine neurons by repeated administration of haloperidol: analysis using in vivo intracellular recording. J Pharmacol Exp Ther 238:10921100.

Hainsworth AH, Röper J, Kapoor R, Ashcroft FM (1991) Identification and electrophysiology of isolated pars compacta neurons from guinea-pig substantia nigra. Neuroscience 43 : 81-93.

Hauber W (2010) Dopamine release in the prefrontal cortex and striatum: Temporal and behavioural aspects. Pharmacopsychiatry 43: S32-S41.

Häusser M, Stuart G, Racca C, Sakmann B (1995) Axonal initiation and active dendritic propagation of action potentials in substantia nigra neurons. Neuron 15:637-647.

Heien ML, Wightman RM (2006) Phasic dopamine signaling during behavior, reward, and disease states. CNS Neurol Disord Drug Targets 5:99-108.

Hines ML, Carnevale NT (1997) The NEURON simulation environment. Neural Comput 9:1179-1209.

Hyland BI, Reynolds JN, Hay J, Perk CG, Miller R (2002) Firing modes of midbrain dopamine cells in the freely moving rat. Neuroscience 114:475492.

Khaliq ZM, Bean BP (2010) Pacemaking in dopaminergic ventral tegmental area neurons: depolarizing drive from background and voltagedependent sodium conductances. J Neurosci 30:7401-7413.

Kita T, Kita H, Kitai ST (1986) Electrical membrane properties of rat substantia nigra compacta neurons in an in vitro slice preparation. Brain Res 372:21-30.

Kullmann PH, Wheeler DW, Beacom J, Horn JP (2004) Implementation of a fast 16-bit dynamic clamp using LabVIEW-RT. J Neurophysiol 91:542554.

Kuznetsova AY, Huertas MA, Kuznetsov AS, Paladini CA, Canavier CC (2010) Regulation of firing frequency in a computational model of a midbrain dopaminergic neuron. J Comput Neurosci 28:389-403.

Lacey MG, Mercuri NB, North RA (1989) Two cell types in rat substantia nigra zona compacta distinguished by membrane properties and the actions of dopamine and opioids. J Neurosci 9:1233-1241.

Mercuri NB, Bonci A, Calabresi P, Stratta F, Stefani A, Bernardi G (1994) Effects of dihydropyridine calcium antagonists on rat midbrain dopaminergic neurones. Br J Pharmacol 113:831-838.

Milescu LS, Yamanishi T, Ptak K, Smith JC (2010) Kinetic properties and
B

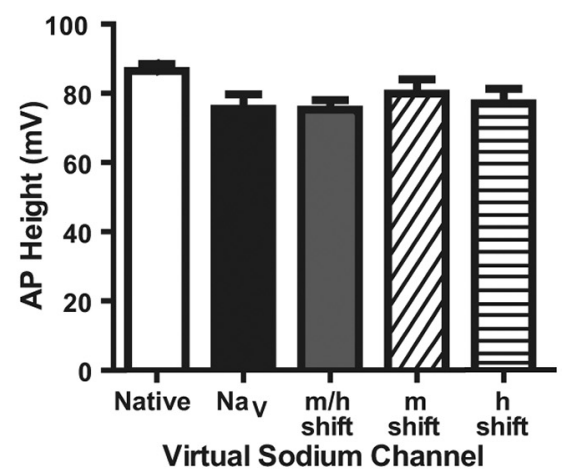

C

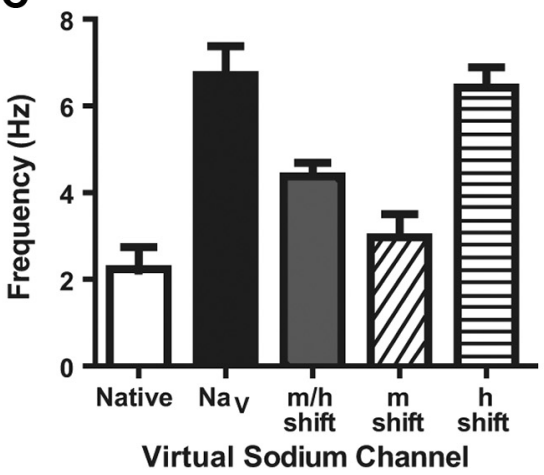


A

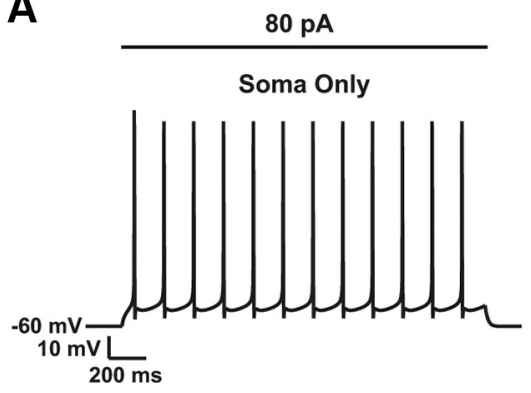

Soma $8 \mathrm{X}>$ Dendrite

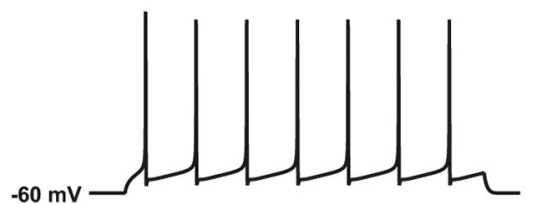

Soma 2.5X > Dendrite

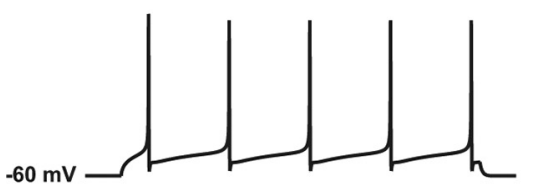

Soma $=$ Dendrite

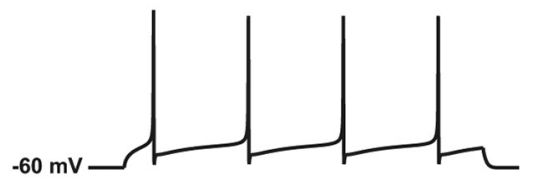

Dendrite Only

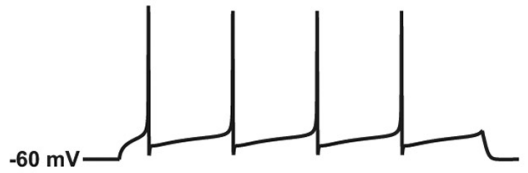

B
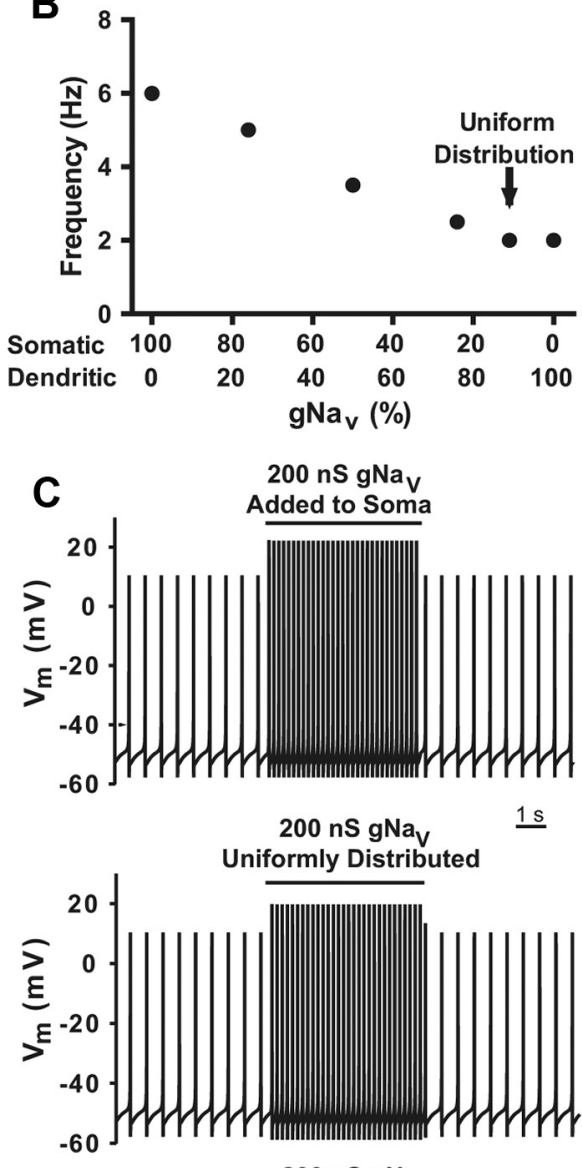

$200 \mathrm{nS} \mathrm{gNa}_{V}$

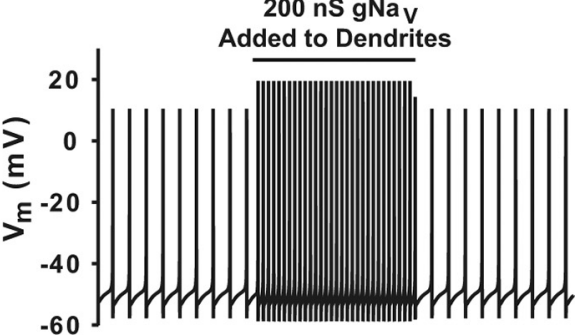

Figure 12. Simulation predictions of frequency with differential somatodendritic $\mathrm{Na}_{\mathrm{V}}$ channel distribution. $\boldsymbol{A}$, Simulated activity of model SN DA neuron held at $-60 \mathrm{mV}$ and stimulated with a $2 \mathrm{~s}, 80 \mathrm{pA}$ current injection, and $845 \mathrm{nS}$ of g $\mathrm{gaa}_{\mathrm{v}}$ was distributed across the $23.75 \mathrm{pF}$ of the $C_{\mathrm{m}}$ of the soma and the $191.31 \mathrm{pF} C_{\mathrm{m}}$ of the dendrites at varying ratios. The traces in $A$, from top to bottom, have the following somatic/dendritic $\mathrm{Na}_{\mathrm{v}}$ current densities in $\mathrm{nS} / \mathrm{pF}$ : Soma Only $=35.6 / 0$, Soma $8 \times>$ Dendrite $=17.8 / 2.2$, Soma $2.5 \times>$ Dendrite $=8.4 / 3.4$, Soma $=$ Dendrite $=3.9$ uniformly distributed, and Dendrite Only $=0 / 4.4$. B, Spiking frequency as a result of changing the percentage distribution of $845 \mathrm{nS}$ of $\mathrm{gNa}_{\mathrm{v}}$ between the soma and dendrites in the DA neuron compartmental model as demonstrated in A. C, Simulated current-clamp recordings from a pacing model neuron to which $200 \mathrm{nS}$ of $\mathrm{gNa}_{\mathrm{v}}$ was added to the soma (top), uniformly distributed (middle), or added to the dendrites only (bottom).

channel functional properties between dopamine and GABA neurons of the rat substantia nigra. J Neurophysiol 103:3099-3114.

Shao D, Okuse K, Djamgoz MB (2009) Proteinprotein interactions involving voltage-gated sodium channels: Post-translational regulation, intracellular trafficking and functional expression. Int J Biochem Cell Biol 41:14711481.

Skarsfeldt T (1992) Electrophysiological profile of the new atypical neuroleptic, sertindole, on midbrain dopamine neurones in rats: Acute and repeated treatment. Synapse 10:25-33.

Skarsfeldt T, Perregaard J (1990) Sertindole, a new neuroleptic with extreme selectivity on A10 versus A9 dopamine neurones in the rat. Eur J Pharmacol 182:613-614.

Ting JT, Feng G (2011) Improved methods for acute brain slice preparation from adult and aging brain. In: Program No. 520.29. 2011 Neuroscience Meeting Planner. Soc Neurosci Abstr 37:505.12.

Tischbirek CH, Wenzel EM, Zheng F, Huth T, Amato D, Trapp S, Denker A, Welzel O, Lueke K, Svetlitchny A, Rauh M, Deusser J, Schwab A, Rizzoli SO, Henkel AW, Müller CP, Alzheimer C, Kornhuber J, Groemer TW (2012) Use-dependent inhibition of synaptic transmission by the secretion of intravesicularly accumulated antipsychotic drugs. Neuron 74 : $830-844$

Valenti O, Cifelli P, Gill KM, Grace AA (2011) Antipsychotic drugs rapidly induce dopamine neuron depolarization block in a developmental rat model of schizophrenia. J Neurosci 31:12330-12338.

Vetter P, Roth A, Häusser M (2001) Propagation of action potentials in dendrites depends on dendritic morphology. J Neurophysiol 85:926-937.

Wang W, Richerson GB (1999) Development of chemosensitivity of rat medullary raphe neurons. Neuroscience 90:1001-1011.

White FJ, Wang RY (1983a) Differential effects of classical and atypical antipsychotic drugs on A9 and A10 dopamine neurons. Science 221:1054-1057.

White FJ, Wang RY (1983b) Comparison of the effects of chronic haloperidol treatment on $\mathrm{A} 9$ and $\mathrm{A} 10$ dopamine neurons in the rat. Life Sci 32:983-993.

Zhang L, Sykes KT, Buhler AV, Hammond DL (2006) Electrophysiological heterogeneity of spinally projecting serotonergic and nonserotonergic neurons in the rostral ventromedial medulla. J Neurophysiol 95:1853-1863. 